\title{
The Cleaning of Aluminum Frame Assembly Units
}

\author{
T.H. Shen
}

May 16, 2001

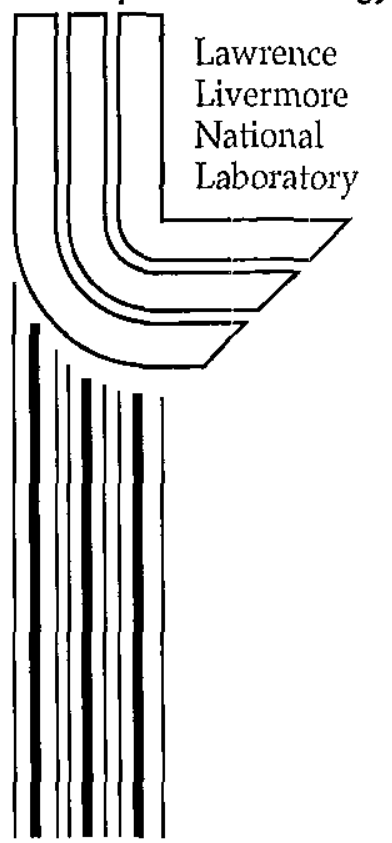




\section{DISCLAIMER}

This document was prepared as an account of work sponsored by an agency of the United States Government. Neither the United States Government nor the University of California nor any of their employees, makes any warranty, express or implied, or assumes any legal liability or responsibility for the accuracy, completeness, or usefulness of any information, apparatus, product, or process disclosed, or represents that its use would not infringe privately owned rights. Reference herein to any specific commercial product, process, or service by trade name, trademark, manufacturer, or otherwise, does not necessarily constitute or imply its endorsement, recommendation, or favoring by the United States Government or the University of California. The views and opinions of authors expressed herein do not necessarily state or reflect those of the United States Government or the University of California, and shall not be used for advertising or product endorsement purposes.

This work was performed under the auspices of the U. S. Department of Energy by the University of California, Lawrence Livermore National Laboratory under Contract No. W-7405-Eng-48.

This report has been reproduced

directly from the best available copy.

Available to DOE and DOE contractors from the

Office of Scientific and Technical Information

P.O. Box 62, Oak Ridge, TN 37831

Prices available from (423) 576-8401

http://apollo.osti.gov/bridge/

Available to the public from the

National Technical Information Service

U.S. Department of Commerce

5285 Port Royal Rd.,

Springfield, VA 22161

http://www.ntis.gov/

OR

Lawrence Livermore National Laboratory

Technical Information Department's Digital Library

http://www.llnl.gov/tid/Library.html 


\title{
The Cleaning of Aluminum Frame Assembly Units
}

\author{
Tien H. Shen \\ Materials Science and Technology Division \\ Chemistry \& Materials Science Directorate \\ Lawrence Livermore National Laboratory
}

\begin{abstract}
The Brulin immersion and the precision cleaning experiments have shown that neither the Brulin solution nor the precision cleaning in AstroPak causes the smut formation on aluminum surfaces. The acid-bath cleaning in GTC is the primary source of the smut formation. The current GTC acid formulation etches the aluminum matrix quite aggressively, but does not appear to appreciably attack the Si particles. Therefore, this acid-bath cleaning will leave the castaluminum part surfaces with many protruded Si particles, which could potentially cause smut problems in the cleaning process down-stream. To ensure the removal of all loose Si particles from the cast-aluminum parts, it is necessary to physically hand-wipe and vigorously wash the acid-bath cleaned surfaces. Furthermore, the casting porosity in alloy A356 could be another source in causing high swipe readings in the FAU parts.
\end{abstract}

*******************************************************

\section{INTRODUCTION}

In January 2001, the frame assembly units (FAUs) for the NIF Amplifier Buses appeared to develop "smut" following the precision cleaning at AstroPak. As shown in Appendix A-1", the swipe readings taken from the FAUs \#7490, \#7578, \#8083, \#8084 and \#8086 had a cleanliness level ${ }^{\S}$ ranging from 85 to 153 , which far exceeded the acceptable cleanliness level of 83 . It was not clear at the time what was the cause of this smut formation on the supposedly precisioncleaned FAUs. Several possibilities were postulated as the source of the smut which include:

- contamination during the transportation and storage of the precision-cleaned FAUs,

- the precision cleaning process at AstroPak,

- the manufacturing process at General Tool Corp.(GTC),

- a combination of various cleaning processes and the material itself.

$\S$ The cleanliness level is defined by the MIL-STD-1246C specification. 
A task force, led by Doug Larson and Ernie More, was put together in early February to address the amplifier cleanliness issue. This report summarizes the results of several experiments conducted between February to April, 2001 to understand the smut formation mechanism in the cleaning of aluminum FAUs.

Nature of the smut Figure 1 shows the configuration of a FAU for the NIF amplifier. The top and bottom are made of cast aluminum alloy A356 and the sides and posts are fabricated from extruded aluminum alloy 6061-T651. Table I lists the nominal compositions of these two aluminum alloys.

Table I Nominal chemical compositions of alloys A356 and 6061.

\begin{tabular}{|c|c|c|c|c|c|c|c|c|c|}
\hline wt \% & $\mathbf{S i}$ & $\mathbf{M g}$ & $\mathbf{C u}$ & $\mathbf{C r}$ & $\mathbf{T i}$ & $\mathbf{F e}$ & $\mathbf{M n}$ & $\mathbf{Z n}$ & $\mathbf{A l}$ \\
\hline $\mathbf{A 3 5 6}$ & $6.7-7.5$ & $0.25-0.45$ & $0.2^{*}$ & & $0.2^{*}$ & $0.2^{*}$ & $0.1^{*}$ & $0.1^{*}$ & balance \\
\hline $\mathbf{6 0 6 1}$ & $0.4-0.8$ & $0.8-1.2$ & $0.15-0.4$ & $04-.35$ & $0.15^{*}$ & $0.7^{*}$ & $0.15^{*}$ & $0.25^{*}$ & balance \\
\hline
\end{tabular}

Figure 2 shows the typical microstructures of these two alloys. The $\mathrm{Al}_{13}(\mathrm{Fe}, \mathrm{Cr})_{3} \mathrm{Si}$ (often referred to as the $\alpha$-eutectic) are the typical second phase particles in all aluminum alloys formed by impurity elements such as $\mathrm{Fe}, \mathrm{Mn}, \mathrm{Cr}, \mathrm{Si}$, etc. In addition to the $\alpha$-eutectic particles, the cast A356 alloy also contains a larger amount of pure Si particles and some cast porosity.

Generally speaking, the cast A356 parts have higher swipe readings compared with that of the extruded 6061 parts. The particles from the swipe have been analyzed by Ed Lindsey using the energy dispersive $x$-ray spectrometry (EDXS) in a scanning electron microscope (SEM) ${ }^{2}$. Figure 3 shows a typical EDXS result of the particles in the swipe obtained from the A356 and 6061 parts. A detailed listing of these results compiled by Phil Miller is provided in the Appendix A-2. A swipe sample to gather a large amount of smut from an A356 part was also analyzed by Cheng Saw using X-ray diffraction(XRD). The results of the SEM/EDXS and XRD analyses are summarized as follows:

1) More than half of the particles analyzed in the A.356 swipe are Si particles and the rest of the particles contain $\mathrm{Ca}, \mathrm{O}$ and $\mathrm{Cl}$.

2) The XRD result ${ }^{3}$ confirmed the EDXS/SEM analysis that the Si peaks in the EDXS are indeed caused by the elemental silicon.

3) The majority of the particles taken from alloy 6061 swipe contain very little $\mathrm{Si}$, but rather other elements such as $\mathrm{Fe}, \mathrm{Cr}, \mathrm{Ti}, \mathrm{Al}$ and $\mathrm{Mg}$.

All these results are consistent with our understanding of the difference between these two alloys in the second phase particles as shown in Figure 2. Furthermore, these results do not match the signature of the common "dirt", which is heavily composed of calcium-aluminosilicates ${ }^{4}$. Hence we concluded early in the investigation that the "dirt" that might have penetrated the wrappings was not the cause of the problem. Since the majority of the smut came from the aluminum alloy itself and not from the contamination during the transportation and storage of the precision- 
cleaned FAUs, this suggests that some aspect of the cleaning process generated the smut in the FAUs.

The Cleaning of a FAU The FAUs are manufactured by GTC in Cincinnati and precisioncleaned by AstroPak in Livermore. The cleaning process of a FAU involves several steps as follows:

1) Each FAU component is high pressure sprayed with 3\% Brulin 1990GD at $130^{\circ} \mathrm{F}$ followed by a high pressure water rinse.

2) The cleaned part is immediately immersed in an acid-bath containing $10 \mathrm{vol} \%$ $\mathrm{HNO}_{3}+0.2 \mathrm{~g} / \ell \mathrm{K}_{2} \mathrm{Cr}_{2} \mathrm{O}_{7}+0.5 \mathrm{vol} \% \mathrm{HF}$ (referred to as the GTC acid from now on) for 10 minutes, followed by a high pressure Brulin spray/water rinse.

3) The acid-bath cleaned parts are assembled, packaged and sent to AstroPak for the precision cleaning.

4) The precision cleaning of the FAU in AstroPak uses 3\% Brulin 1990GD at 110 to $130^{\circ} \mathrm{F}$ with pressure in the range of 1000 to $2500 \mathrm{psi}$. The cleaning cycle uses three high pressure Brulin spray/DI water rinse cycles followed by three high pressure Zonyl/DI water rinse cycles (referred to as the AstroPak Revision $\mathrm{C}$ procedure). The FAU is then dried with nitrogen.

A $3 \%$ to $5 \%$ Brulin solution has a typical pH value of 10 . It was not clear whether the Brulin solution by itself will etch the surface of the aluminum parts. A series of experiments $5,6,7,8$ were conducted to identify the source of the smut formation in the cleaning process. This report documents the results.

\section{Experimental Procedures}

Brulin Immersion Experiment The objective of this experiment is to determine whether the Brulin solution causes smut formation. The experimental procedures are as follows:

1. Obtained three panels each of aluminum alloys A356 and 6061-T6 each 11" square.

2. Machined panel surfaces to a finish typical of a FAU.

3. Solvent-wiped clean to remove any gross dirt.

4. Immersed the three panels in Brulin solutions of $3 \%, 5 \%$ and $8 \%$, respectively, at $160^{\circ} \mathrm{F}$ for 20 minutes.

5. Rinsed panels twice in $130-150^{\circ} \mathrm{F} 18 \mathrm{M} \Omega$ DI water.

6. Air dried.

7. Swipe readings were taken after 24 hours by AstroPak.

To better detect the etching of aluminum surfaces, two mirror-polished samples were also included in the $8 \%$ Brulin immersion experiment. 
Precision Cleaning Experiment The objective of this experiment is to determine the combined effect of the Brulin solution and high pressure spray on the smut formation. The experimental procedures used at AstroPak are as follows:

1. Obtained three 11" $\times 11$ " machined-panels each of aluminum alloys A356 and 6061-T6.

2. Solvent-wiped the surfaces to remove any gross dirt.

3. Reserved one panel each as a control.

4. Cleaned with $3 \%$ and $5 \%$ Brulin solutions, respectively, at $130^{\circ} \mathrm{F}$. The simulated clean/rinse cycle is as follows:

Clean/rinse cycle:
a. Brulin clean $2500 \mathrm{psi} / 30 \mathrm{sec}$.
b. rinse with DI water $2500 \mathrm{psi} / 30 \mathrm{sec}$.
c. Brulin clean $2500 \mathrm{psi} / 30 \mathrm{sec}$.
d. rinse with DI water $2500 \mathrm{psi} / 30 \mathrm{sec}$.

5. Dried with nitrogen and waited for 24 hours before taking swipe reading (including the control samples).

Several mirror-polished samples were also included in the $5 \%$ Brulin clean/rinse experiment to better detect the etching if it occurs.

Acid-bath Cleaning Experiment The objective of this experiment is to determine the effect of acid-bath cleaning on the smut formation of aluminum parts. This experiment was designed to generate a surface similar to that of the FAU manufactured by GTC and study the progressive change in the surface morphology of alloys A356 and 6061 throughout the whole cleaning process. The experimental procedures are as follows:

1. Prepared two 1" $\times 1$ " coupons of A356 alloy with one surface in as-machined condition and the other surface in mirror-polished condition.

2. Documented both surfaces in a known location with metallography and SEM.

3. Dipped samples in either Acid A (GTC acid) or Acid B as follows:

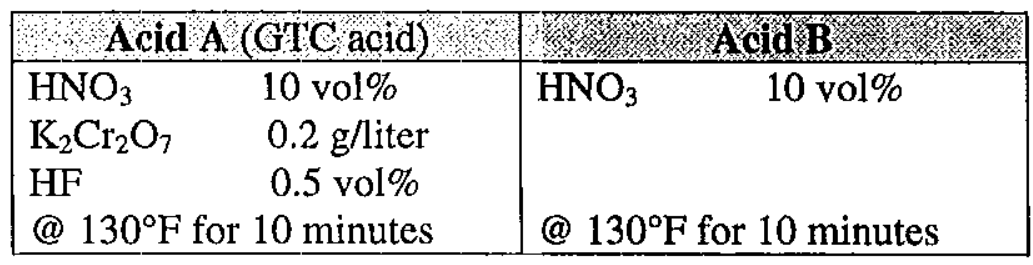

The purpose of using Acid B was to simulate the condition when the dichromate and HF concentration exhausted in GTC acid after cleaning too many aluminum parts.

4. Documented the acid-cleaned surfaces on the known location with SEM.

5. Samples were precision-cleaned in AstroPak using the procedure outlined in the previous section. 
6. Documented the precision-cleaned surfaces on the known location with SEM.

7. Samples were swiped with filter paper to simulate the swipe reading process.

8. Documented both surfaces on the known location with SEM.

Two 11" $x 11$ " panels each of alloys A356 and 6061 with as-machined surfaces were also subjected to the acid-bath cleaning experiments using the procedures outlined above except that the bath temperature was reduced to $86^{\circ} \mathrm{F}$. The swipe readings were taken after the acid-bath cleaning and the precision cleaning. These four panels were also subjected to the aerosol testing.

\section{RESULTS}

Brulin Immersion Experiment Table II lists the swipe readings of the panels subjected to the Brulin immersion test.

Table II Cleanliness level of swipe readings after Brulin immersion.

\begin{tabular}{|c|c|c|}
\cline { 2 - 3 } \multicolumn{1}{c|}{} & $\mathbf{A 3 5 6}$ & $\mathbf{6 0 6 1 1 6} \mathbf{6}$ \\
\hline Control & 82 & 77 \\
\hline $3 \%$ Brulin & 81 & 96 \\
\hline $5 \%$ Brulin & 110 & 101 \\
\hline $8 \%$ Brulin & 91 & 95 \\
\hline
\end{tabular}

These results are inconclusive as to whether the Brulin caused the etching of aluminum surfaces. The increase in swipe readings in Brulin-cleaned samples was likely caused by the Brulin residue left on the surfaces due to insufficient rinse and contamination during the bagging and transportation of the test panels for swipe reading in AstroPak.

The more definitive test is to examine the surfaces with metallography or SEM. Figure 4 shows the SEM study of A356 samples immersed in $3 \%, 5 \%$ and $8 \%$ Brulin solutions at $160^{\circ} \mathrm{F}$ for 20 minutes. There were no signs of etching of sample surfaces by the Brulin solution. Figure 5 shows the mirror-polished samples (A356 \& 6061-T6) immersed in 8\% Brulin solution at $160^{\circ} \mathrm{F}$ for 20 minutes. Again, Brulin did not show any signs of etching of the sample surfaces.

Precision Cleaning Experiment Table III lists the swipe readings on the six test panels following the precision cleaning at AstroPak.

Table III Cleanliness level of swipe readings after the precision cleaning in AstroPak.

\begin{tabular}{|c|c|c|}
\cline { 2 - 3 } \multicolumn{1}{c|}{} & $\mathbf{A 3 5 6}$ & 156 \\
\hline Control & 119 & 87 \\
\hline $3 \%$ Brulin & 88 & 73 \\
\hline $5 \%$ Brulin & 76 & 6061606 \\
\hline
\end{tabular}


These results suggested that the precision cleaning removed the surface contaminants quite effectively. Figure 6 shows a mirror-polished A356 sample that was precision-cleaned with $3 \%$ Brulin. Precision cleaning didn't show any signs of etching on the sample surface. However, the precision cleaning could create extra deposits if the cleaning/rinse steps were not applied properly. Figure 7 shows the extra deposits on a precision cleaned surface on a mirror-polished A356 sample. These surface deposits were analyzed by EDXS in SEM. Figure 8 shows that these deposits, Particles A, B and F, contain O, Na, P, S and K. Although the formulation of the Brulin is not available, these deposits are likely to be the residual Brulin detergent. In discussing this result with AstroPak, their experience showed that if the Brulin solution was left dried before the DI water rinse, the Brulin would stay on the surface and could not be easily removed by the subsequent Brulin spray/DI water rinse process.

Acid-bath Cleaning Figure 9 shows the effects of Acid A and precision cleaning on a mirrorpolished surface of an A356 alloy. The Acid A substantially etched the aluminum matrix and the $\alpha$-eutectic particles, and left the Si particles protruding out of the surface. This can be seen by comparing Figures $9 \mathbf{a}$ to $9 \mathbf{b}$. The depth of the etching was estimated optically to be around $13 \mu \mathrm{m}$. By carefully comparing the same Si particles before and after the acid cleaning, no evidence suggests that the Si particles were attacked by the Acid A. The precision cleaning after the acid-bath cleaning removed some of the protruding Si particles as shown in Figures 9c. The filter paper swipe did not noticeably change the morphology of Si particles as shown in Figure 9d.

The Acid B, on the other hand, showed only a minor etching of the aluminum surface as shown in Figure10. However, the Acid B did aggressively attack the $\alpha$-eutectic particles as shown in Figure 11.

Figure 12 shows the effects of Acid $\mathbf{A}$ and precision cleaning on an as-machined surface of an A356 alloy. These surfaces are more representative of the surfaces of the FAU parts after the acid-bath cleaning in GTC. The Acid A aggressively attacked the as-machined surfaces and left the morphology with no resemblance of the original surface as shown in Figures 12a and $\mathbf{1 2 b}$. The precision cleaning seems to remove more Si particles compared to that of the mirrorpolished sample. This was likely caused by the cracking of the Si particles during the machining of the A356 sample as shown in Figure 13. Again, Figure 14 shows that the Acid B only slightly etched the as-machined surface of an A356 sample.

The swipe readings of the 11" $\times 11$ "test panels cleaned by Acid A and Acid B followed by the precision cleaning are listed in Table IV.

Table IV The results of swipe readings after the acid-bath cleaning and precision cleaning.

\begin{tabular}{|c|c|c|c|c|}
\hline & $\begin{array}{c}\text { Acld } \\
A 356\end{array}$ & 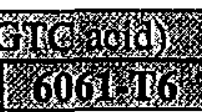 & 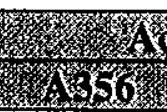 & $\frac{a^{6}}{60}$ \\
\hline After acid-bath cleaning & 242 & 140 & 112 & 105 \\
\hline
\end{tabular}




\begin{tabular}{|c|c|c|c|c|}
\hline $\begin{array}{c}24 \text { hours after the precision } \\
\text { cleaning in AstroPak }\end{array}$ & 81 & 83 & 85 & 108 \\
\hline $\begin{array}{c}4 \text { days after the precision } \\
\text { cleaning in AstroPak }\end{array}$ & 92 & 104 & 91 & 85 \\
\hline
\end{tabular}

The high swipe readings from the Acid A cleaned surfaces compared with the Acid B cleaned A356 and 6061 samples agree with the results of the topographical studies as shown from Figures 9 through 14. The Acid A left many Si particles either loosely attached to the surface or protruded out of the surface that were subjected to being easily broken off by the subsequent cleaning process. This is the primary source of the smut formation in A356 alloy. For alloy 6061 , the amount of second phase particles is much less compared with that of the A356. Thus, the swipe readings are lower. The precision cleaning in this experiment effectively removed the loose particles from the parts surfaces. After four days of drying, the swipe readings elevated slightly as often observed in the FAUs.

Figure 15 shows the results of the aerosol testing. All four panels passed the specification of less than 100 particles $(>0.5 \mu \mathrm{m}) / \mathrm{ft}^{3}$ after 60 flash lamp shots. The A356 generated a higher level of aerosol compared to that of the 6061 alloy. After 55 shots, there was no significant difference in the aerosol level between the Acid A versus the Acid B cleaned panels. Although prior to that, it appears that the Acid A cleaned parts have a somewhat lower rate of aerosol formation.

\section{Drscussions}

Acid-bath Cleaning The Brulin immersion and the precision cleaning experiments have shown that neither the Brulin solution nor the precision cleaning in AstroPak can cause the smut formation on aluminum surfaces. Thus, the acid-bath cleaning in GTC is the likely source of the smut formation in the FAUs.

The acid-bath cleaning experiment has clearly demonstrated that the Acid A (GTC acid) aggressively attacked the aluminum surface and the Acid B (10 vol\% $\left.\mathrm{HNO}_{3}\right)$ showed only a minor etching effect. 'The $0.5 \% \mathrm{HF}$ is known to attack the aluminum aggressively, and the addition of potassium dichromate was proposed to enhance the etching of $\mathrm{Si}^{9,10}$. However, the current results indicate that the GTC acid formulation didn't noticeably attack the Si particles at least in the current experimental conditions of $130^{\circ} \mathrm{F}$ for 10 minutes. This suggests that the reaction kinetics of the $\mathrm{HF}$ with $\mathrm{Al}$ is much faster than that of the dichromate $\left(\mathrm{Cr}_{2} \mathrm{O}_{7}^{-2}\right)$ ion with $\mathrm{Si}$. However, the dichromate did eventually react with the Si particles left in the acid-bath. The color of the acid-bath changed ${ }^{11}$ from bright yellow (which is associated with $\mathrm{Cr}^{+6}$ ions ${ }^{10}$ ) right after the cleaning of the A356 panels to blue-green (which is associated with $\mathrm{Cr}^{+3}$ ions ${ }^{10}$ ) after 24 hours.

The purpose of using Acid B in this experiment was to simulate the condition when the Acid A was exhausted after cleaning too many aluminum parts. The result suggests that the Acid $\mathbf{B}$ is actually better than the Acid A in preventing the smut formation. After the GTC acid cleaning of 
an A356 alloy, the surfaces were left behind with many protruded Si particles. These Si particles were very brittle and many of them have already shown signs of cracking as shown in Figure 13. It would be very easy to dislodge and/or break off these particles during the precision cleaning in AstroPak or during the filter swipe. This explains why the Acid A cleaned aluminum parts have very high swipe readings before the precision cleaning.

The AstroPak Revision D Procedure In an actual production unit, the FAU frame \#8088 was cleaned in GTC right after the replacement of the acid on March 1, 2001. Table V lists the swipe readings reported by AstroPak after two attempts to precision-clean this FAU and after using the Revision D procedure.

Table V The swipe readings reported by AstroPak on frame \#8088 after two attempts of precision cleanings and after the Revision $\mathbf{D}$ procedure.

\begin{tabular}{|c|c|c|c|c|}
\hline & SwipeLocation & $\begin{array}{l}\text { 1t Precision } \\
\text { Clean }(3 / 29 \% 00)\end{array}$ & $\begin{array}{l}\text { 2nd Precision } \\
\text { clean }(3129101)\end{array}$ & $\begin{array}{l}\text { Reys } \\
\text { olean }(3 / 30 / 0) \\
\text { on }\end{array}$ \\
\hline 1 & Top Casting - top surface & 130 & 224 & 133 \\
\hline 2 & Top Casting - top surface & 143 & 198 & 100 \\
\hline 3 & Top Casting - side & 91 & 93 & 69 \\
\hline 4 & Top Casting - side & 102 & 93 & 91 \\
\hline 5 & Top Casting - inside top & 91 & 103 & 83 \\
\hline 6 & Top Casting - inside side & 87 & 203 & 163 \\
\hline 7 & Side Wall - outside surface & 79 & 65 & 68 \\
\hline 8 & Side Wall - inside surface & 88 & 79 & 73 \\
\hline 9 & Bottom Casting - side & 73 & 105 & 77 \\
\hline 10 & Bottom Casting - side & 86 & 99 & 79 \\
\hline 11 & Bottom Casting - inside side & 90 & 96 & 67 \\
\hline 12 & Bottom Casting - inside pocket & 88 & 91 & 74 \\
\hline 13 & Bottom Casting - inside bottom & 100 & 95 & 78 \\
\hline 14 & Bottom Casting - inside pocket & 111 & 85 & 73 \\
\hline 15 & Top Casting - inside pocket & 137 & 147 & 71 \\
\hline 16 & Top Casting - inside pocket & 204 & 120 & 91 \\
\hline & Average & 106 & 119 & 87 \\
\hline
\end{tabular}

The Locations 7 and 8 are parts made from the alloy 6061. The swipe readings are consistently lower in all three cleaning attempts. For the A356 parts, these data clearly show that the GTC acid can potentially cause high swipe readings if the subsequent precision cleaning process was not applied thoroughly. As demonstrated by the AstroPak Revision D procedure, it is necessary to

1) physically hand-wipe the surface with solvents,

2) perform two rigorous precision cleanings with the addition of Zonyl/rinse cycles before/after this solvent wipe,

to completely dislodge and/or break off all loose Si particles in order to reduce the smut reading to an acceptable level. A detailed description of the AstroPak Revision D procedure and the 
additional supporting data are listed in Appendix A-3. Although these results are largely based on test conducted on the FAU made from cast A356 and extruded 6061 alloys, there is no obvious reason not to use the Revision D procedure on wrought 6061 alloy.

Acid Formulation In aluminum industry, the primary purpose ${ }^{12}$ of acid cleaning is to remove smut (undissolved eutectic particles or dispersoids) from the surface after the aluminum parts are first cleaned by a caustic solution. In the current FAU manufacturing scheme in GTC, the aluminum parts are machined, acid-bath cleaned and followed by the final assembly. There was no caustic cleaning involved. The acid-bath cleaning, presumably, serves the purpose of removing organic contaminants and loose debris from part surfaces. Thus, it may not be necessary to add HF and dichromate in the $\mathrm{HNO}_{3}$ because it will only leave the part surfaces with many protruded $\mathrm{Si}$ particles and cause potential smut problems in the down-stream cleaning process.

Previous NIF experiences ${ }^{13}$ suggest that the addition of dichromate may reduce the aerosol level during the frame testing. The current aerosol testing result, as shown in Figure 15, suggests that the acid without the addition of dichromate and HF can also achieve an acceptable aerosol level. However, the current GTC acid formulation has performed quite well from the aerosol point of view. The cost associated with the GTC acid formulation is relatively small compared to the potential negative effects of changing the acid bath to straight $10 \mathrm{vol} \% \mathrm{HNO}_{3}$. Thus, there is no pressing need to change the acid formulation in GTC as long as we can ensure a thorough precision cleaning in Astrolak using the Revision D procedure.

Cast Porosity By reviewing the EDXS results listed in Appendix A-2, some of the particles from A356 swipe contain $\mathrm{Ca}, \mathrm{O}$ and $\mathrm{Cl}$. This suggests that there is another source that may cause high swipe readings in $\mathrm{A} 356$ parts.

During the course of the investigation, six A356 21/2" $\times 2 \frac{1}{2}$ " coupons were mirror-polished in preparation for an experiment. Figure 16 shows that the cast aluminum alloy A356 has extensive cast porosity in the microstructure. These cast porosities could not be seen easily in the as-machined condition but readily revealed in the mirror-polished condition as shown in Figure 16. The amount of porosity varies and depends upon the location in the plate. Based on measurement from a $25 \mathrm{in}^{2}$ area, the area density of the porosity is $185 \pm 15$ per in ${ }^{2}$ with an area ratio of $1.7 \%$. The size of these porosities can be as large as $1 \mathrm{~mm}$ as shown in Figures $\mathbf{1 6 b}$ and 16c. Some of these porosities are interconnected underneath the surface and extend all the way through the thickness of the sample $(\sim 1 / 4)$.

After leaving these six mirror-polished coupons at room temperature for 24 hours, two out of the six coupons developed brownish stains as shown in Figure 17. The locations of these stains were associated with the areas where large $(>1 \mathrm{~mm})$ and deep porosities are located. The back-side (asmachined surface) of these two $2 \frac{1}{2} 2^{\prime \prime} \times 2 \frac{1}{2}$ coupons also contained many large and deep porosities. Again, stains also developed on the back-side but were less noticeable due to the rough machined surfaces. Figure 18 shows the EDXS analysis of the stain around a cast.porosity. The result suggested that aluminum hydroxides may have formed in Areas $\mathbf{2}$ and $\mathbf{3}$ as water was seeping out from the porosity during the air-drying period. 
It has been reported many times during the Amplifier Cleanliness Meeting that the swipe readings of a precision-cleaned FAU could deteriorate as time elapsed (within 24 hours). Several mechanisms that had been postulated include:

- dust/particle contamination after precision cleaning,

- growth of aluminum oxide on part surfaces,

- reduction in electrostatic forces to release surface-adhered particles.

The clean room experiment has ruled out the dust contamination as the cause. The very slow oxide growth rate $^{2}$ as shown in Figure 19, at relative humidity less than $85 \%$, eliminated the oxide growth as a possibility. Thus far, the reduction in electrostatic forces has yet to be proven.

The observation of the stains, developed on a highly polished surface after a 24-hour drying period, offers another possibility that the cast porosity could be a source of the time dependent nature of high swipe readings. The large and deep porosities could potentially

1) trap acid, cleaner (Brulin) and rinse water during various cleaning cycles,

2) release these elements, during drying period, in relatively high concentration back to the surfaces,

3) cause the brownish stains which could be camouflaged by the rough and non-reflective machined surfaces.

This scenario might have occurred in the FAUs if the units were not properly rinsed and dried after the various cleaning processes. The stains might develop in the area of the part surface containing large cast porosity. To minimize the stain caused by the cast porosity, a cleaned surface should be dried with blowing hot air $\left(<160^{\circ} \mathrm{F}\right)$ to drive out all the moisture trapped inside the porosity. 


\section{CONCLUSIONS}

1. The $3 \%$ Brulin solution at $110^{\circ} \mathrm{F}$ to $130^{\circ} \mathrm{F}$ did not etch the aluminum surface.

2. The precision cleaning with $3 \%$ Brulin at $130^{\circ} \mathrm{F}$ combined with the 2,500 psi spray did not etch the aluminum surface.

3. The current acid formulation (GTC acid) etched the aluminum matrix quite aggressively. However, this formulation did not appear to etch the Si particles. Thus, the GTC acid cleaning will leave the part surfaces with many protruding Si particles which could potentially cause smut problems in the down-stream cleaning process.

4. A combination of physical hand-wiping and aggressive washings of the acid-bath cleaned surfaces is necessary to ensure the removal of all loose Si particles particularly in the A356 parts. There is no obvious reason not to use the AstroPak Revision $\mathbf{D}$ procedure on acidcleaned wrought 6061 alloy.

5. Cast porosity in A356 alloy may be responsible for the time dependent nature of the swipe readings.

\section{ACKNOWLEDGEMENTS}

The author would like to express his thanks to Bill Gourdin for many valuable suggestions and comments in the experimental plans, Bob Kershaw and Jim Ferreira in the MS\&T Division for their prompt and high quality services on acid-bath cleaning experiments, metallography and SEM, to Cheng Saw for x-ray diffraction, to Chuck Petty and Dwight Heggins for preparing the test samples, to Phil Miller and Pete Biltoft for setting up and conducting the Brulin and acidbath cleaning experiments on the 11" $\times 11$ " panels, to Ted Werner in AstroPak for conducting many precision cleanings and taking swipe readings, and Andrea Flammini for issuing this report. Many comments and suggestions made by Bill Gourdin, Phil Miller and Ernie More in reviewing this manuscript are also highly appreciated. 


\section{REFERENCES}

1. FAU cleanliness data analyzed by Phil Miller and discussed in the Amplifier Cleanliness Meeting on Feb. 9, 2001.

2. Technical Memo from Tien H. Shen to Bill Gourdin, "Smut Formation in Aluminum Alloys A356 and 6061-T6", February 9, 2001.

3. Technical Memo from Cheng Saw to participants in the Amplifier Cleanliness Meeting, "Surface Containmination in Polished Aluminum A356 Surface", on February 26, 2001.

4. Bill Gourdin, private communication on May 3, 2001.

5. NIF Technical Memo from Tien H. Shen, Phil Miller and Peter Biltoft to participants in the Amplifier Cleanliness Meeting, "Results of Brulin Immersion Experiment", on March 14, 2001.

6. NIF Technical Memo from Tien H. Shen, Bob Kershaw, Jim Ferreira, Ted Werner (AstroPak) to participants in the Amplifier Cleanliness Meeting, "Result of the Precision Cleaning Experiment", on March 16, 2001.

7. NIF Technical Memo from Tien H. Shen, Bob Kershaw, Jim Ferreira and Phil Miller to participants in the Amplifier Cleanliness Meeting, "Determining the Effect of the Acid-bath Cleaning on Smut Formation of Aluminum Parts", on March 26, 2001.

8. NIF Technical Memo from Tien H. Shen and Bob Kershaw to participants in the Amplifier Cleanliness Meeting, "One Possible Source of Causing High Swipe Readings in the FAU Parts", on March 28, 2001.

9. NIF Technical Memo from Phil Miller, Pete Biltoft and Ernie Moor to participants in the Amplifier Cleanliness Meeting, "Chemical Aspects of Acid Cleaning of Aluminum Frame Assembly Units and End Isolator Assemblies”, February 16, 2001.

10. NIF Technical Memo from Phil Miller to participants in the Amplifier Cleanliness Meeting, "Field Deployable Colorimetric Measurement of Dichromate Ion in GTC Acid Cleaning Bath", February 23, 2001.

11. Phil Miller, private communication on March 28, 2001.

12. Aluminum and Aluminum Alloys, ASM Specialty Handbook, The ASM International.

13. Comments made by Ernie More and Chuck Petty in the Amplifier Cleanliness Meeting. 


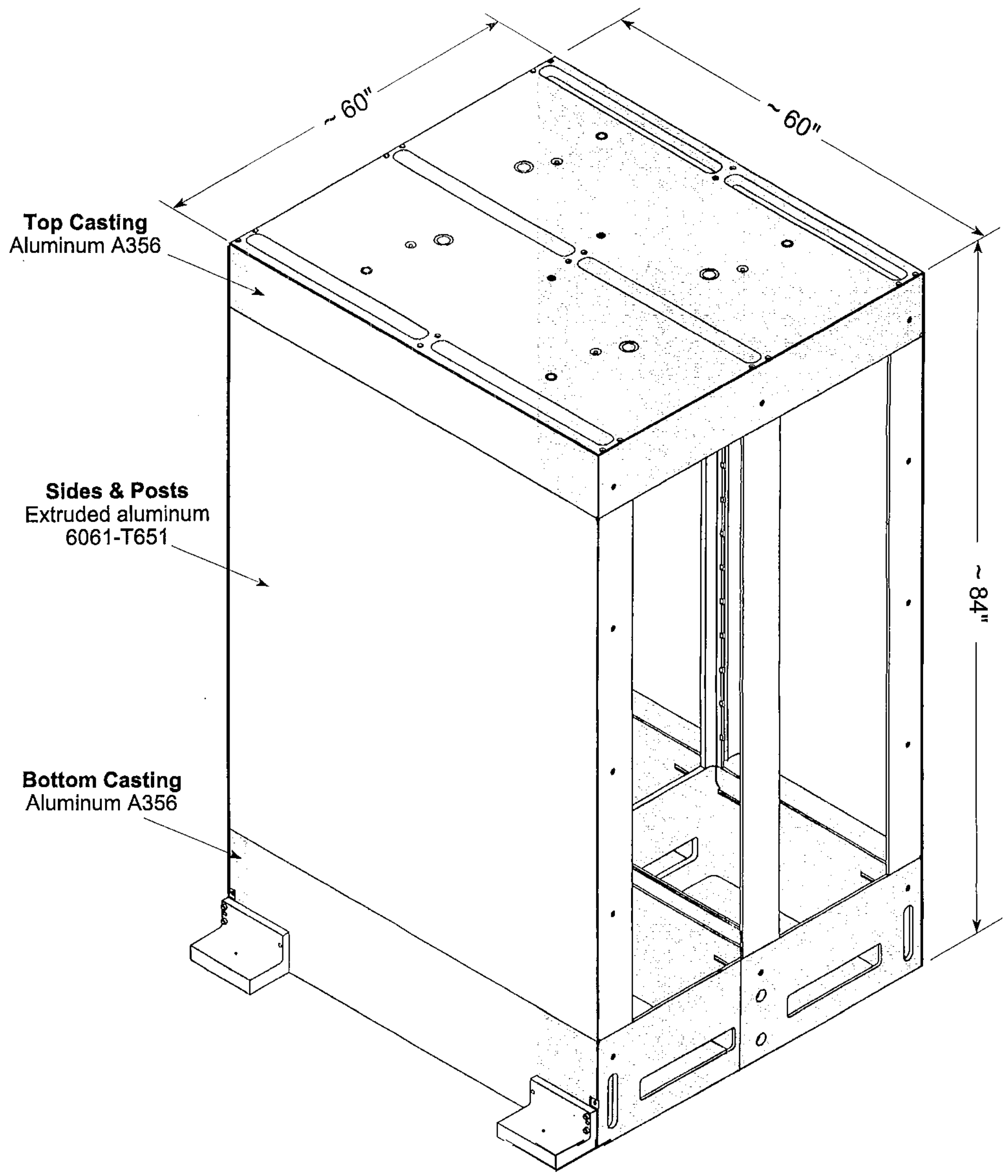

Figure 1 A frame assembly unit (FAU) in the NIF Amplifier Buses. 


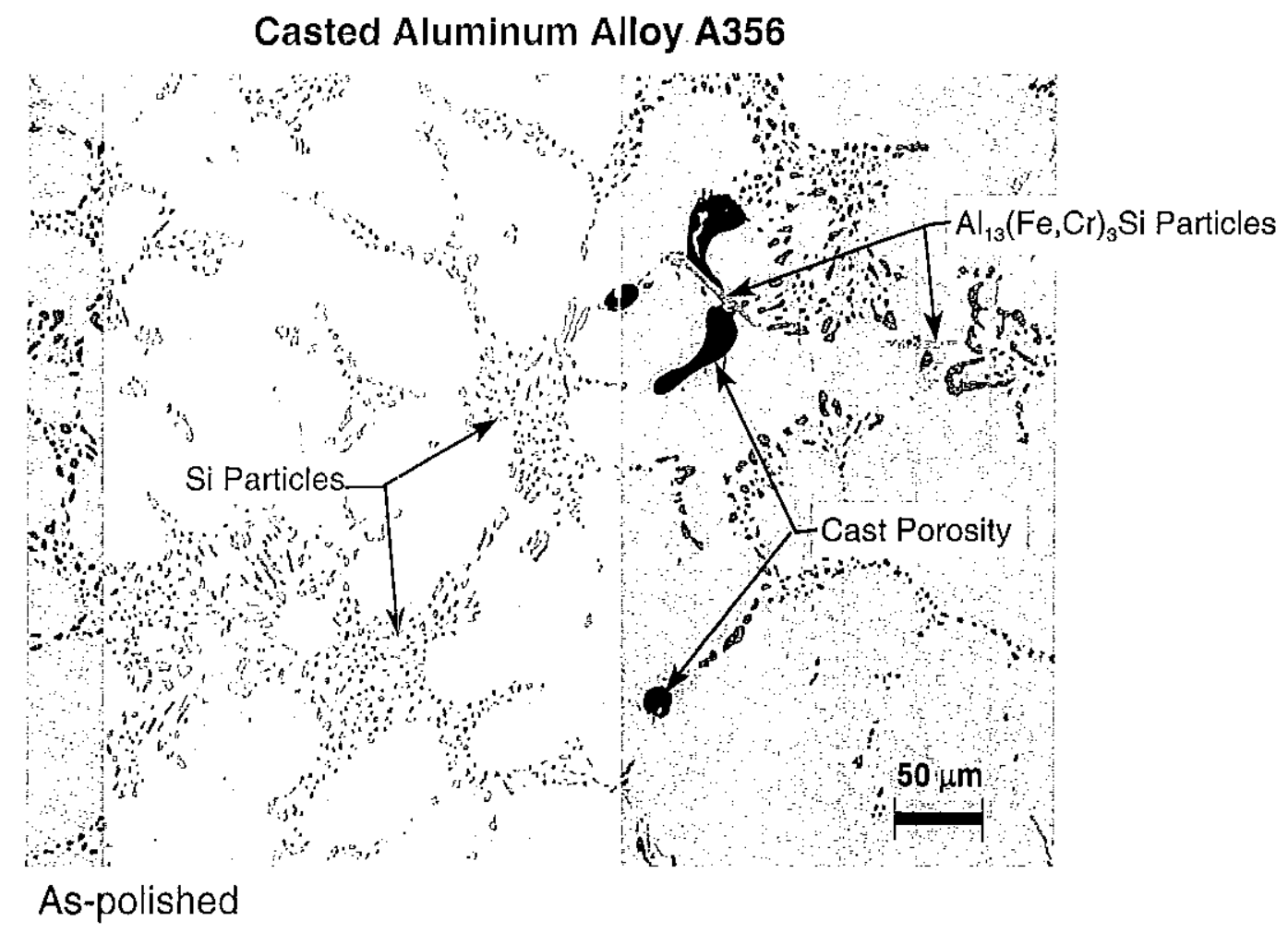

Extruded Aluminum Alloy 6061-T651
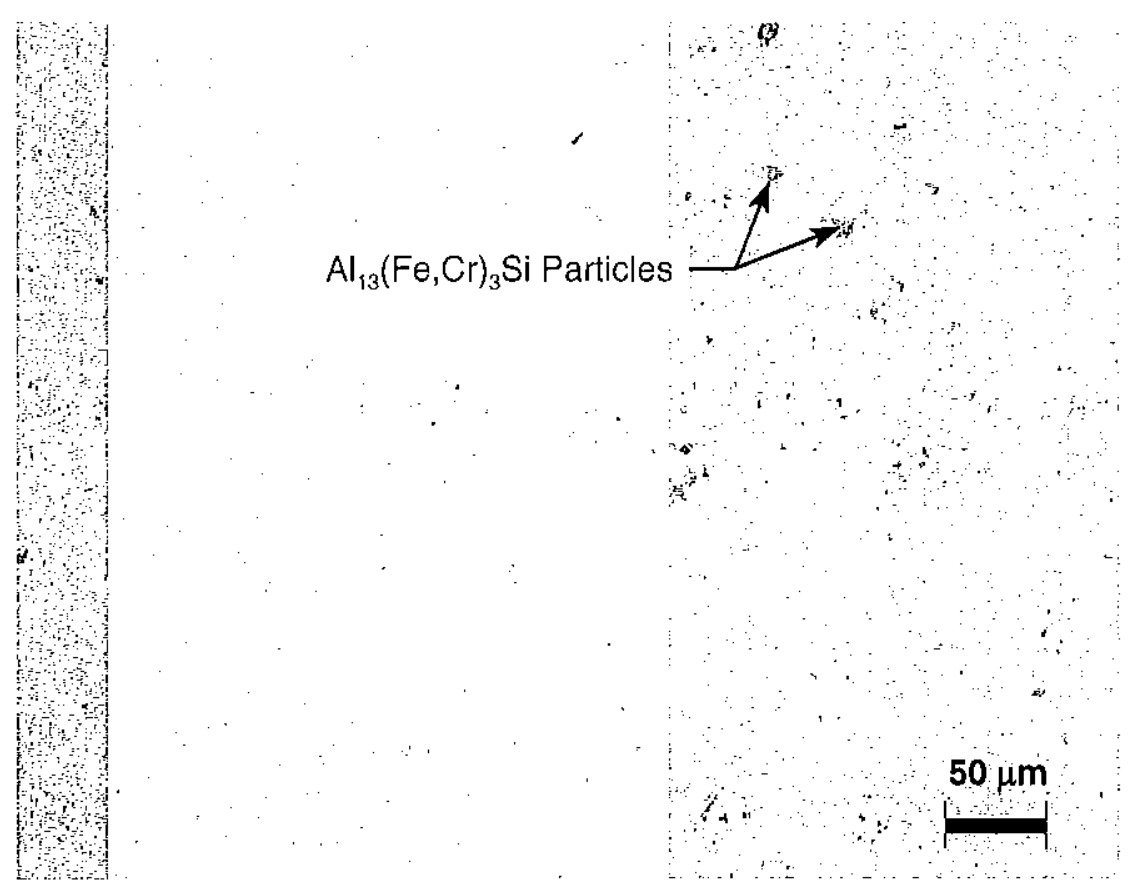

As-polished

Figure 2 Typical microstructures of aluminum alloys A356 and 6061. 


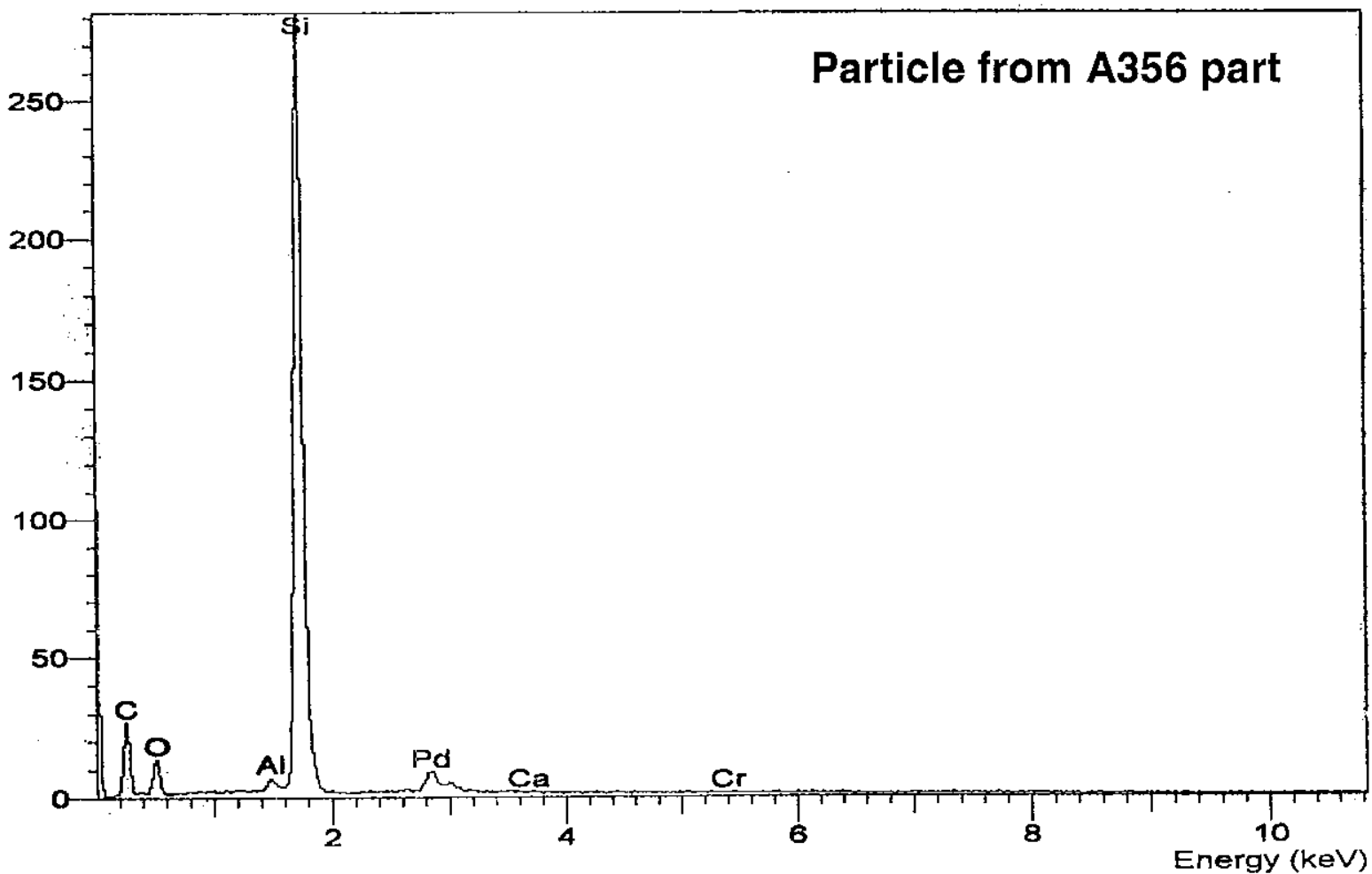

Operator: E. Lindsey TAT

Client : C. Petty. D. Heggins

Job : 55697 sn $104 \# 1 \& \# 4$

cps s/n 104\#1 Part 2 1um (2/2/01 13:51)

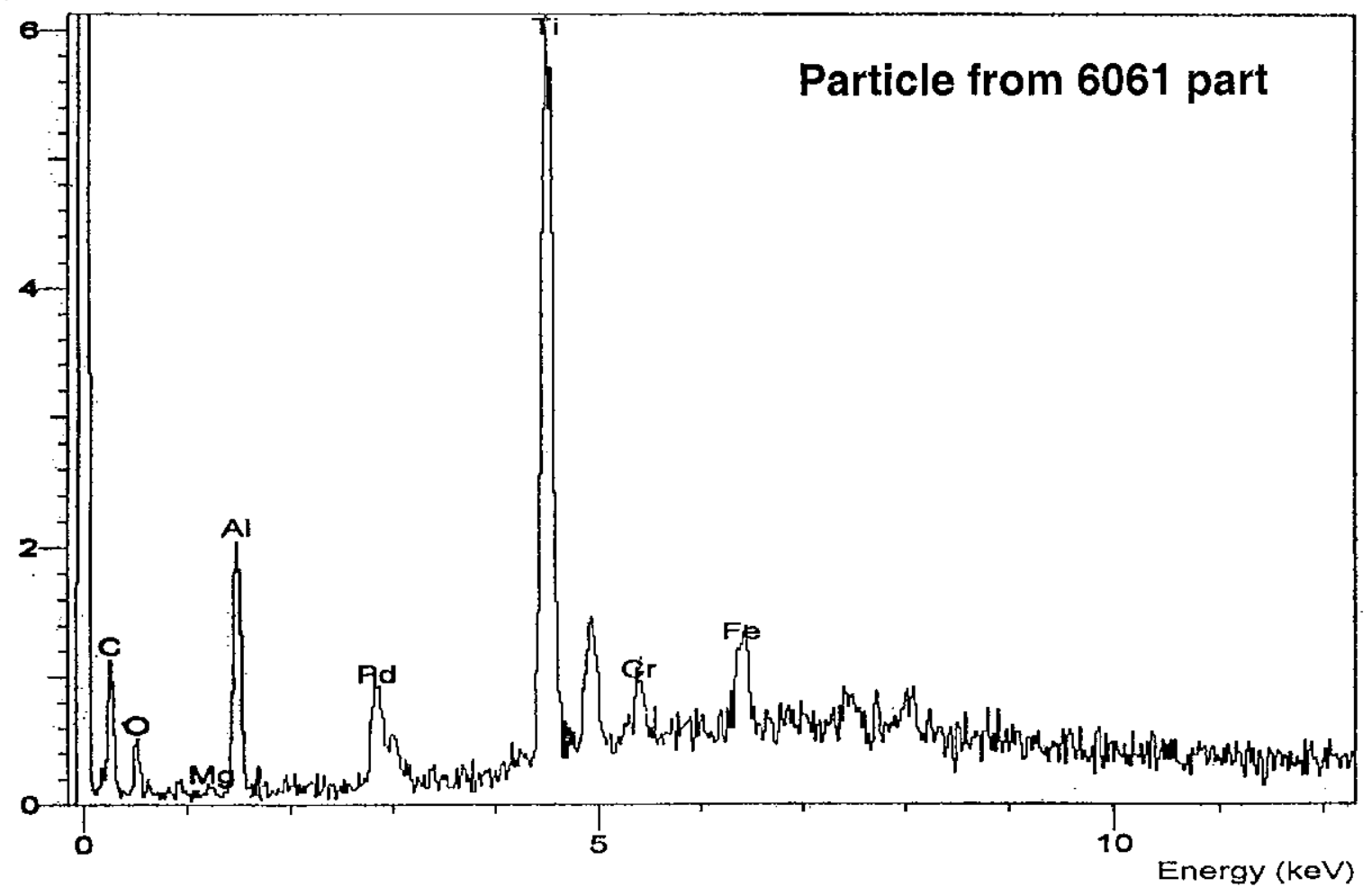

Figure 3 Typical SEM-EDXS of partcles in the swipe paper obtained from A356 and 6061 parts. 


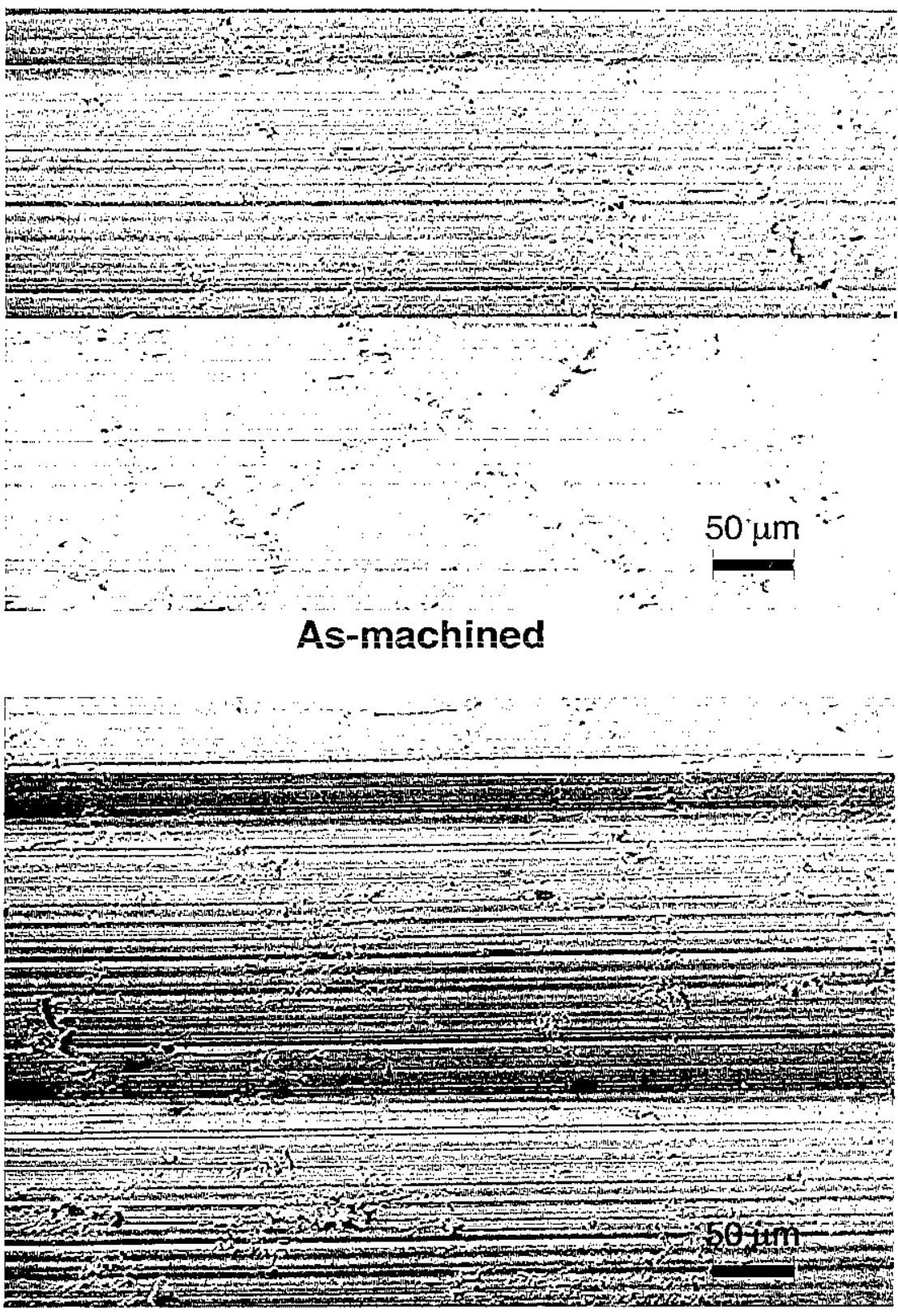

$3 \%$ Brulin at $160^{\circ} \mathrm{F} / 20 \mathrm{~min}$

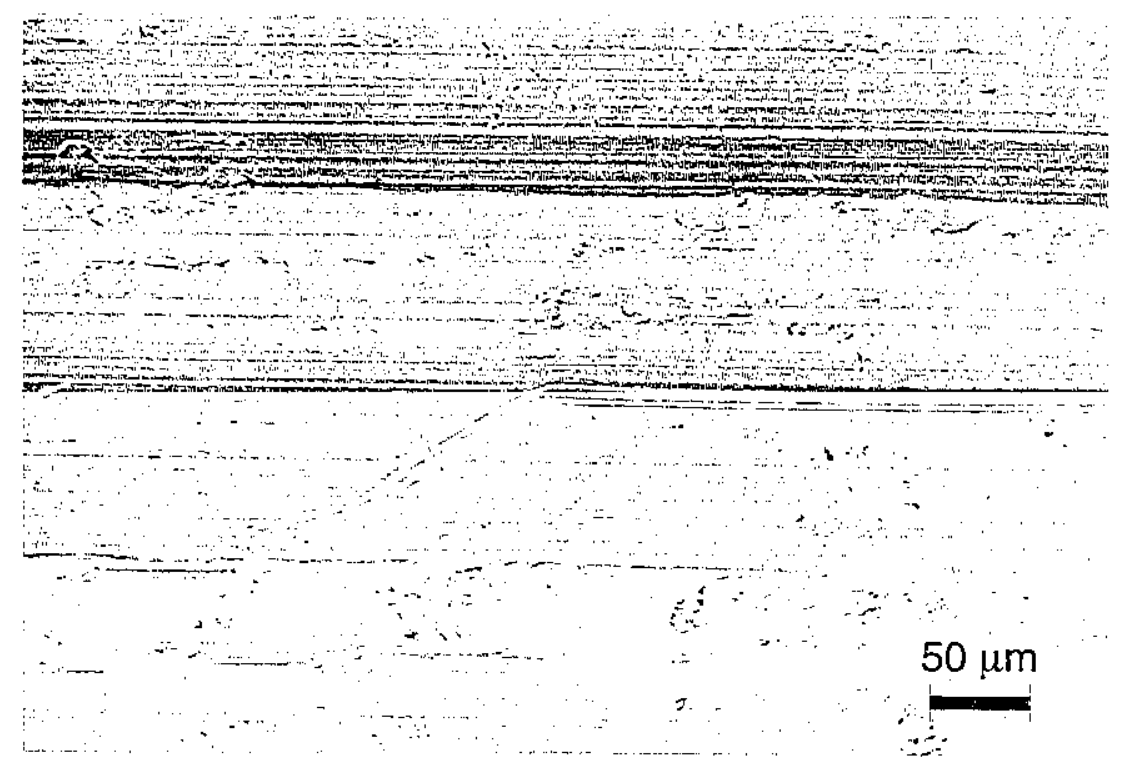

$5 \%$ Brulin at $160^{\circ} \mathrm{F} / 20 \mathrm{~min}$

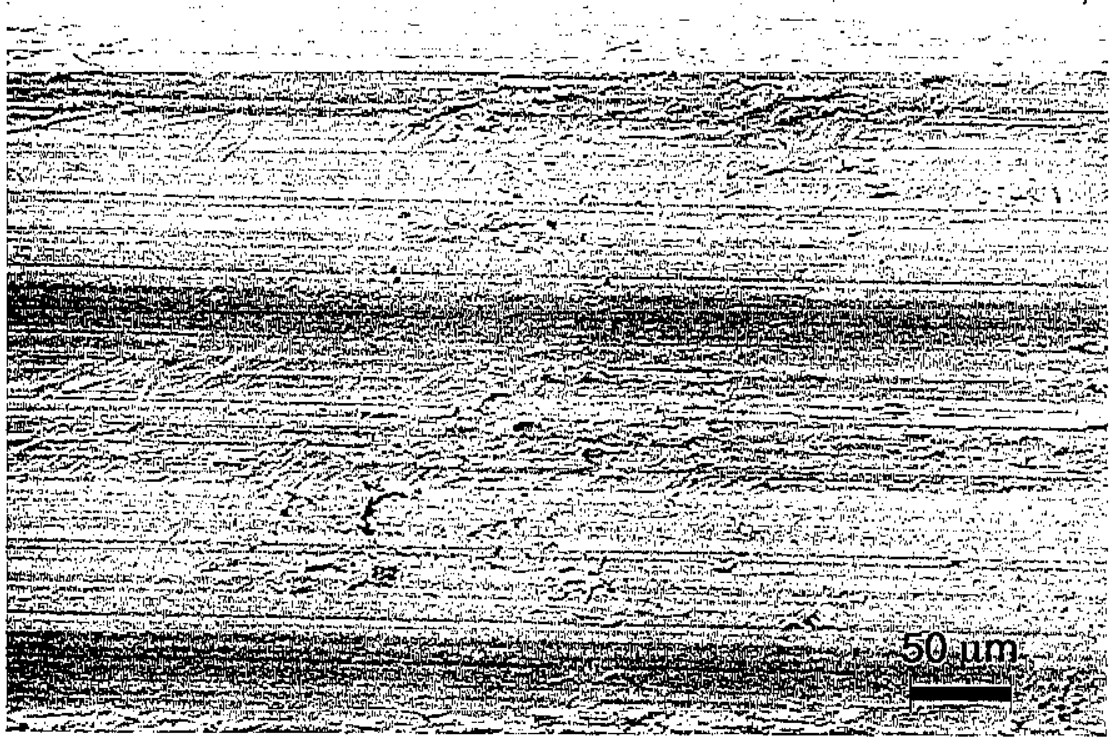

$8 \%$ Brulin at $160^{\circ} \mathrm{F} / 20 \mathrm{~min}$

Figure 4 The SEM Images of A356 samples show no signs of etching after the immersion in $3 \%, 5 \%$ and $8 \%$ Brulin solutions at $160^{\circ} \mathrm{F}$ for 20 minutes. 

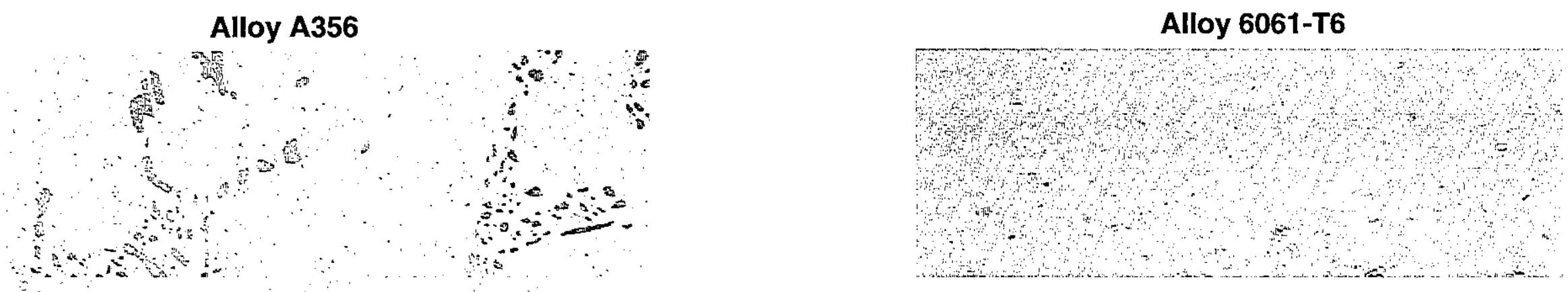

\section{As-polished}

$20 \mu m$

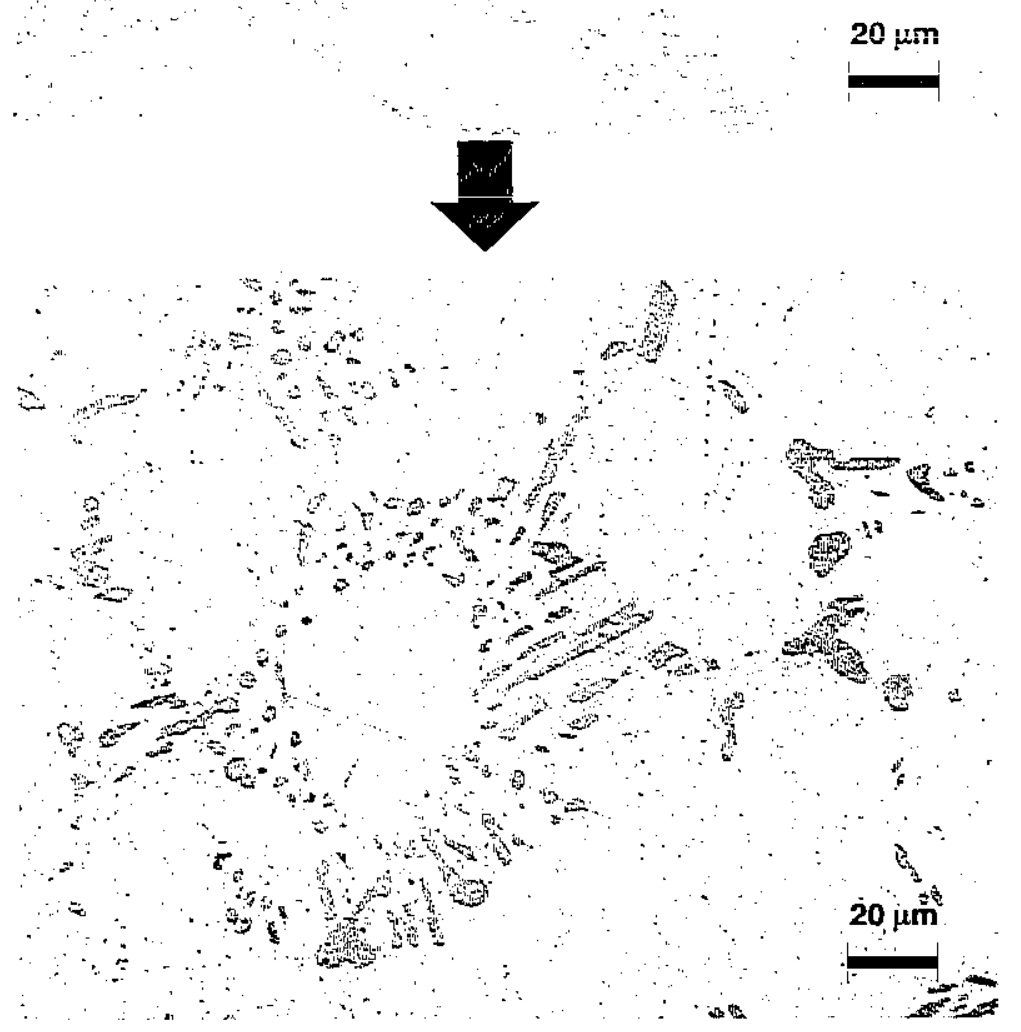

8\% Brulin@ $160^{\circ} \mathrm{F} / 20 \mathrm{~min}$

Figure 5 The mirror-polished samples of A356 and 6061-T6 show no signs of etching after the immersion in $8 \%$ Brulin at $160^{\circ} \mathrm{F}$ for 20 minutes. 
Mirror-polished Surface of an A356 alloy

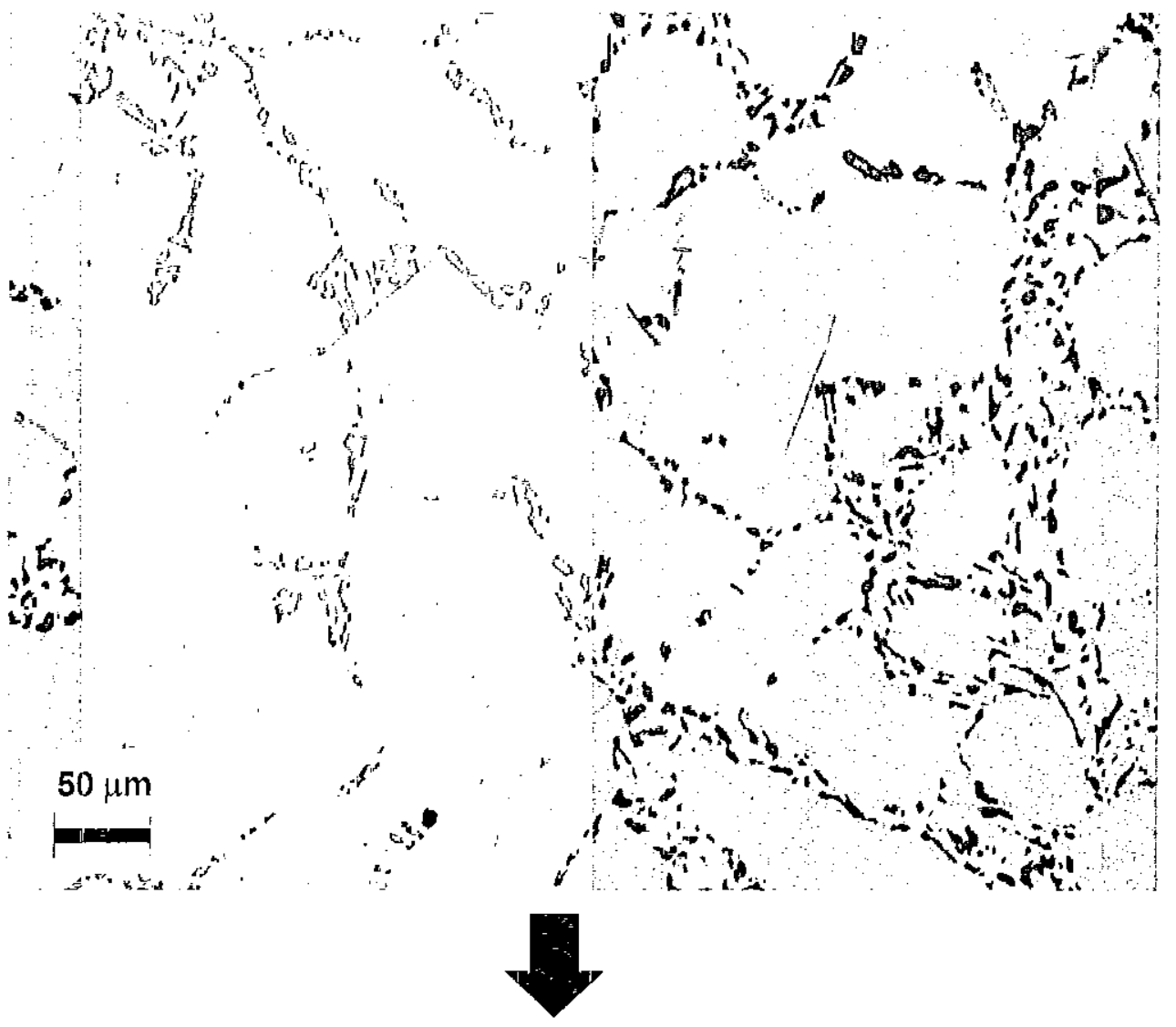

After AstroPak Precision Cleaning

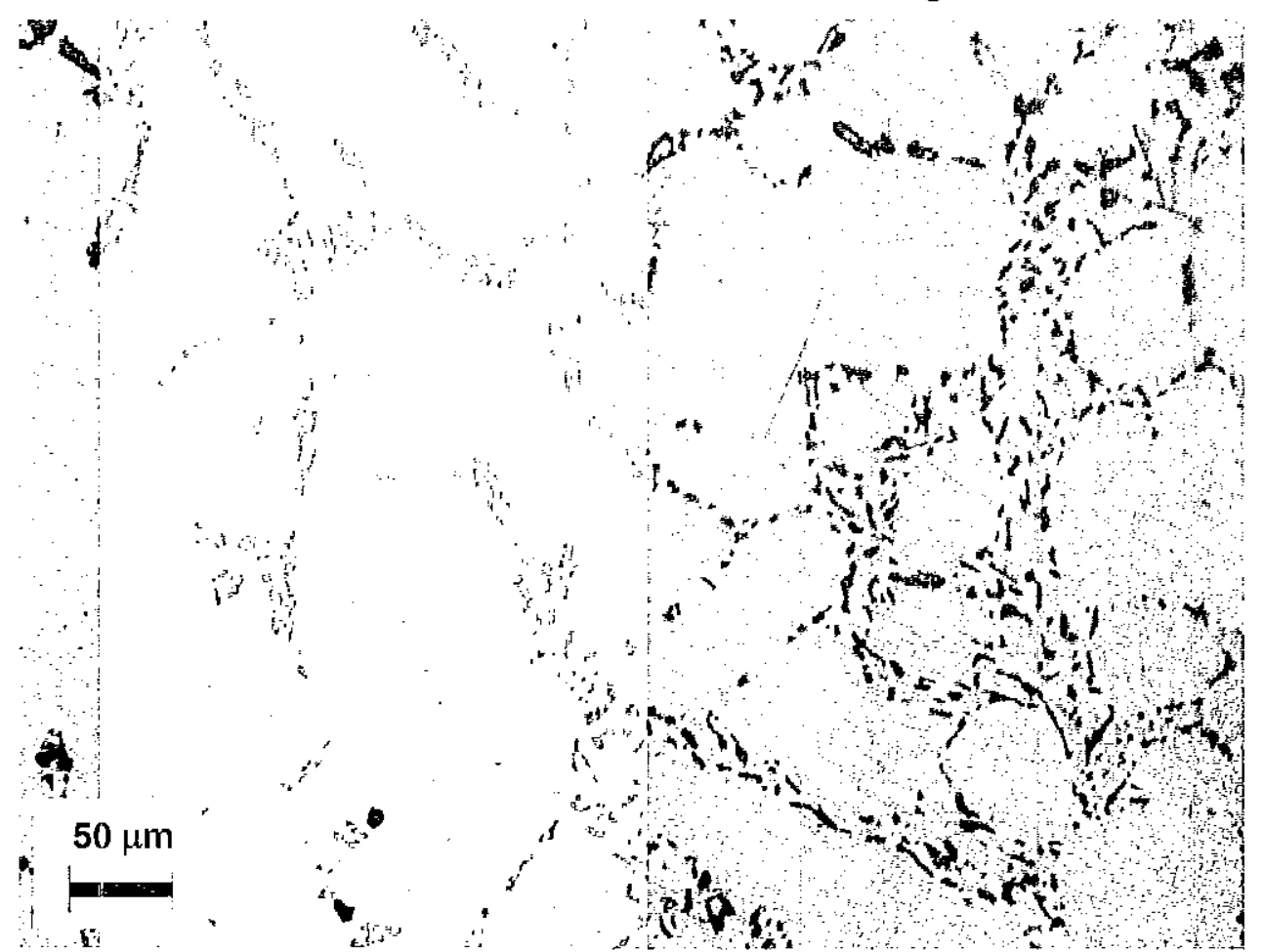

Figure 6 The combination of $3 \%$ Brulin at $130^{\circ} \mathrm{F}$ and the 2,500 psi high pressure spray in the precision cleaning procedure does not etch or attack the surface of an A356 alloy. 
A mirror-polished Surface of an A356 alloy

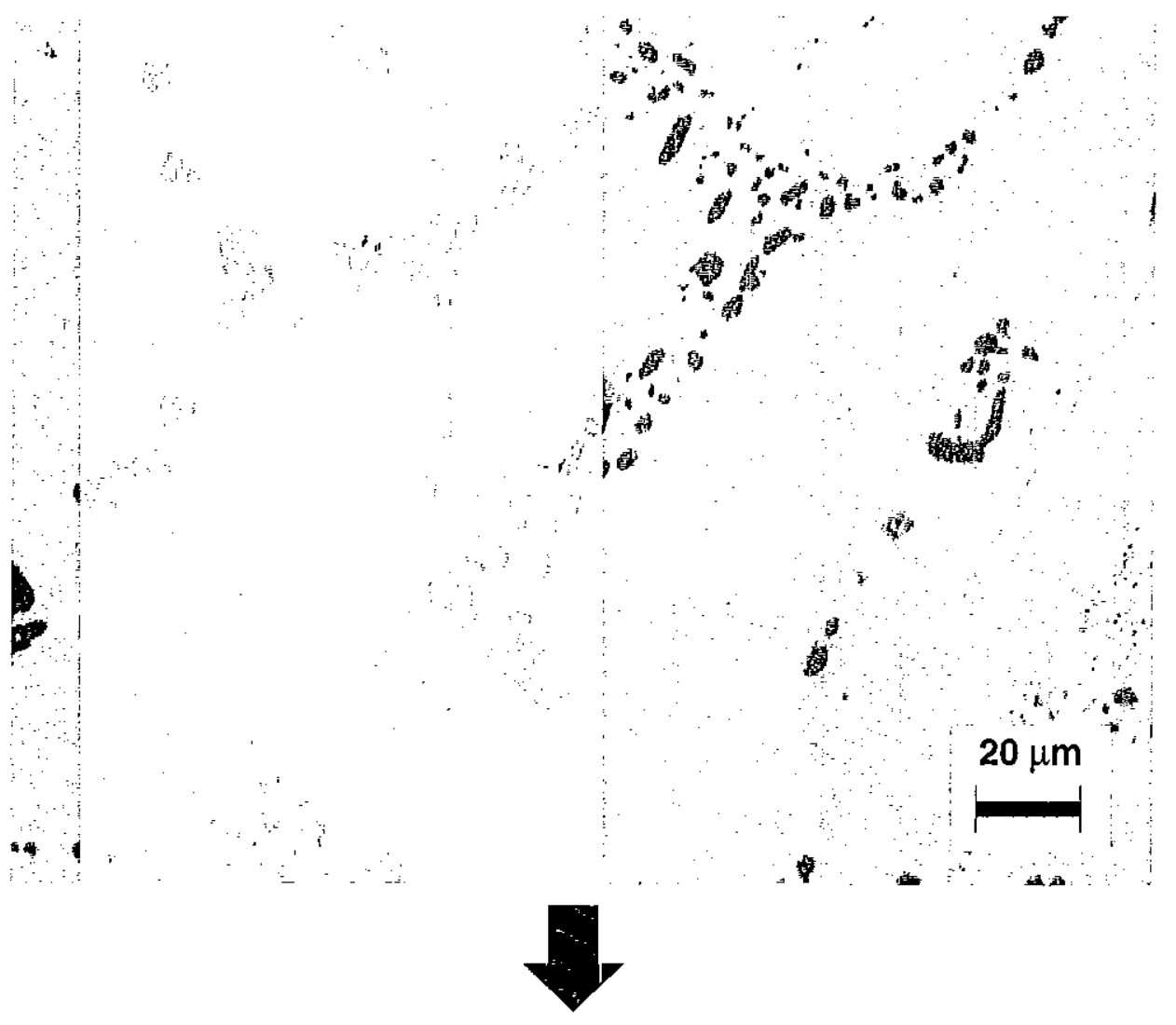

After AstroPak Precision Cleaning

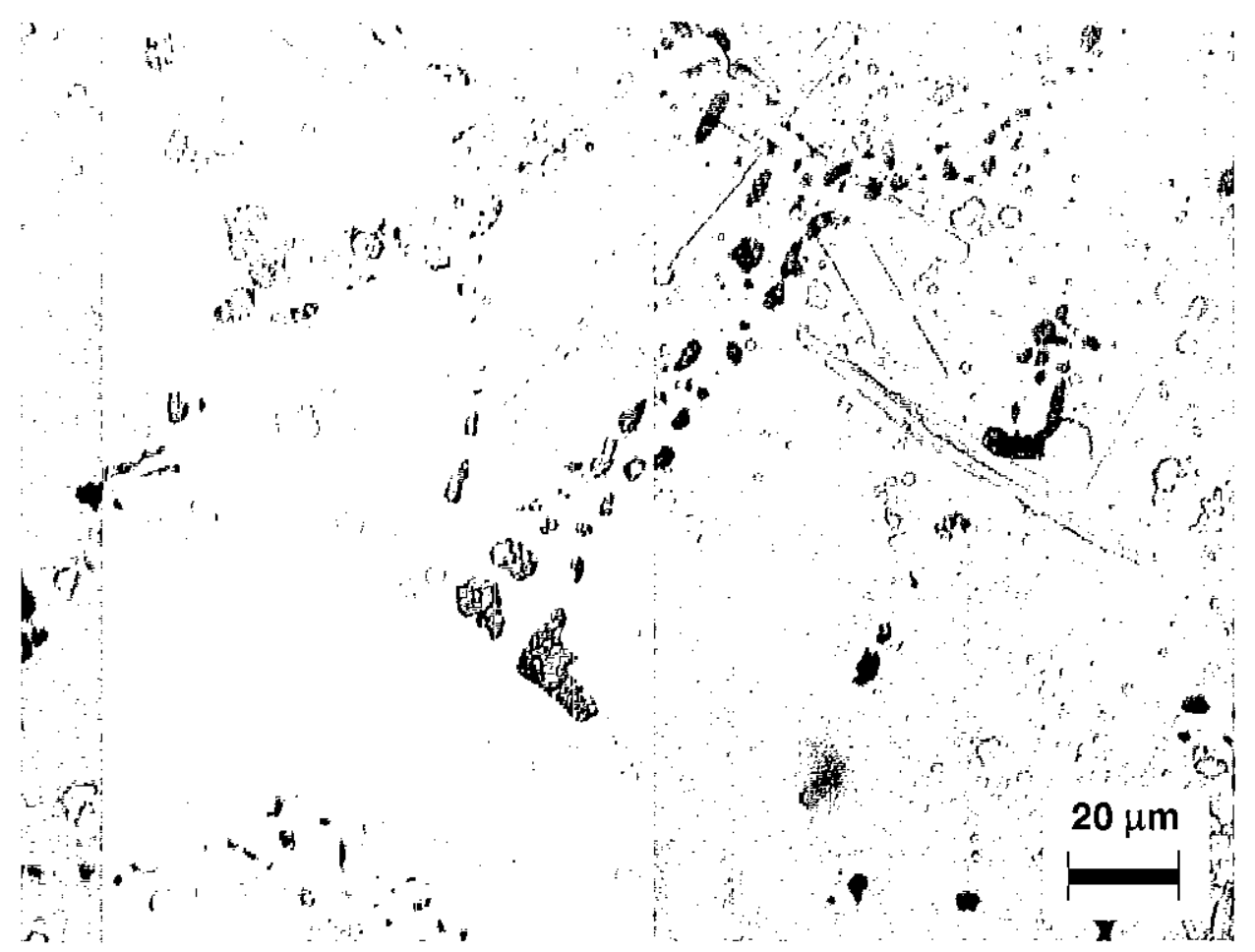

Figure 7 Extra deposits can be created by the precision cleaning process if the Bruiln clean/rinse steps are not applied properly. 

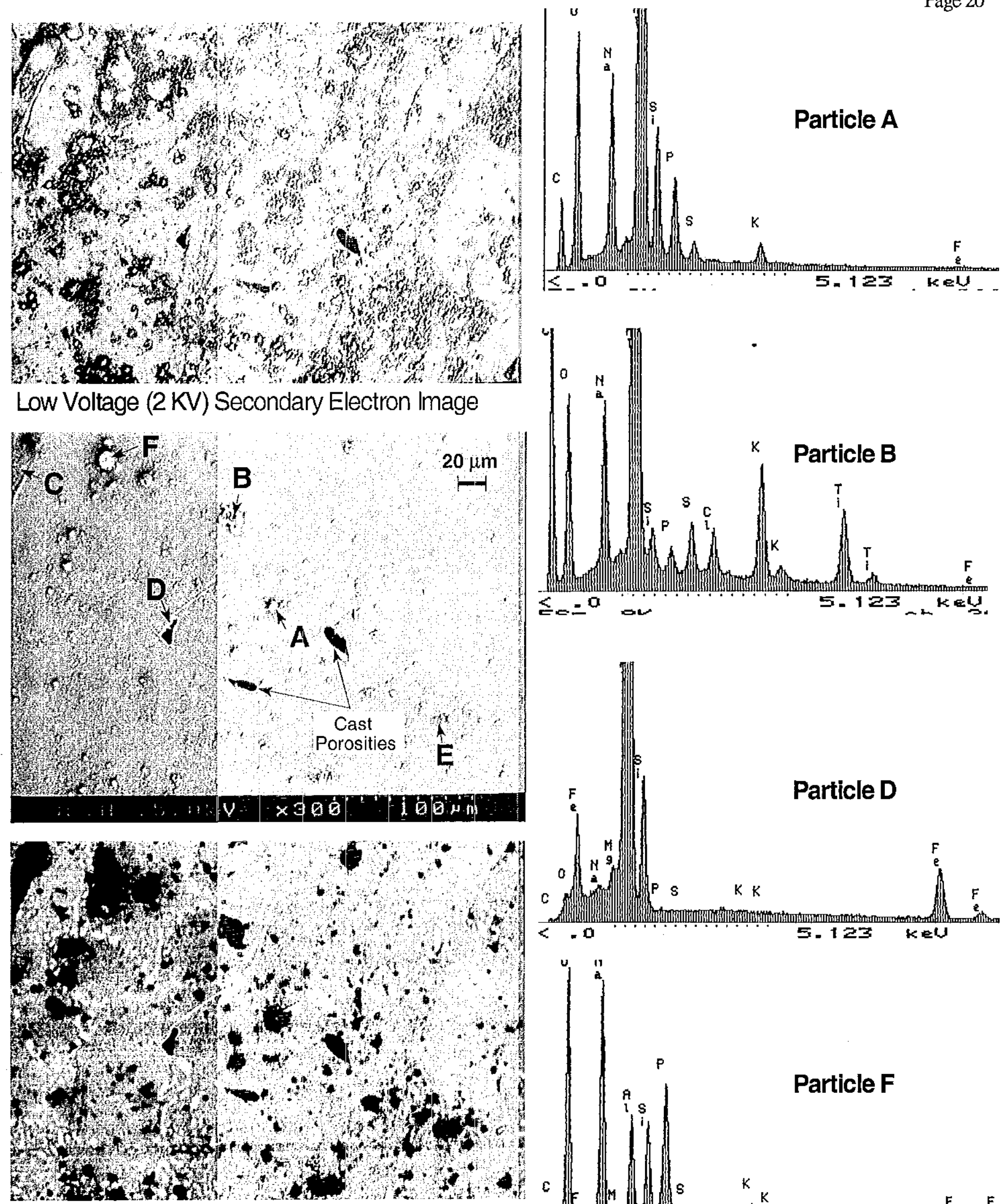
Back-scattering Electron Image

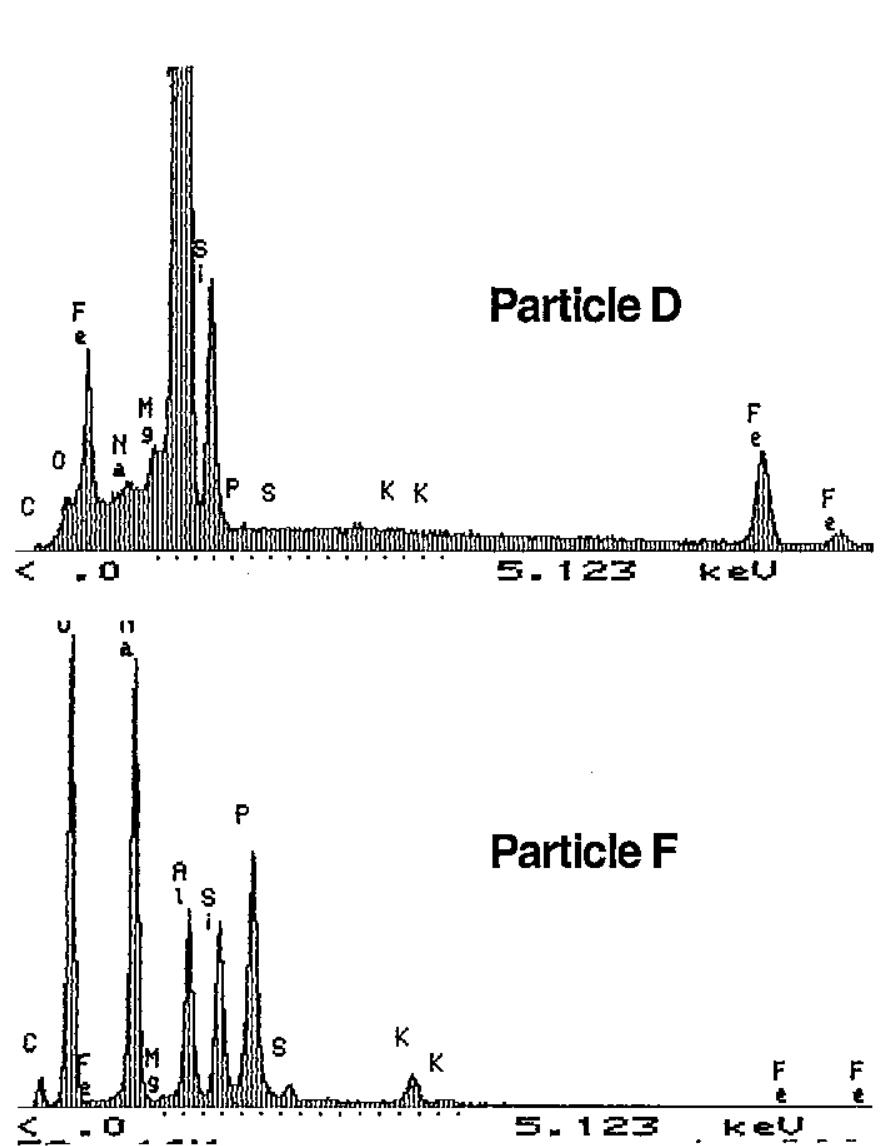

Figure 8 SEM/EDXS analyses of the debris left on the surface after the precision cleaning. 

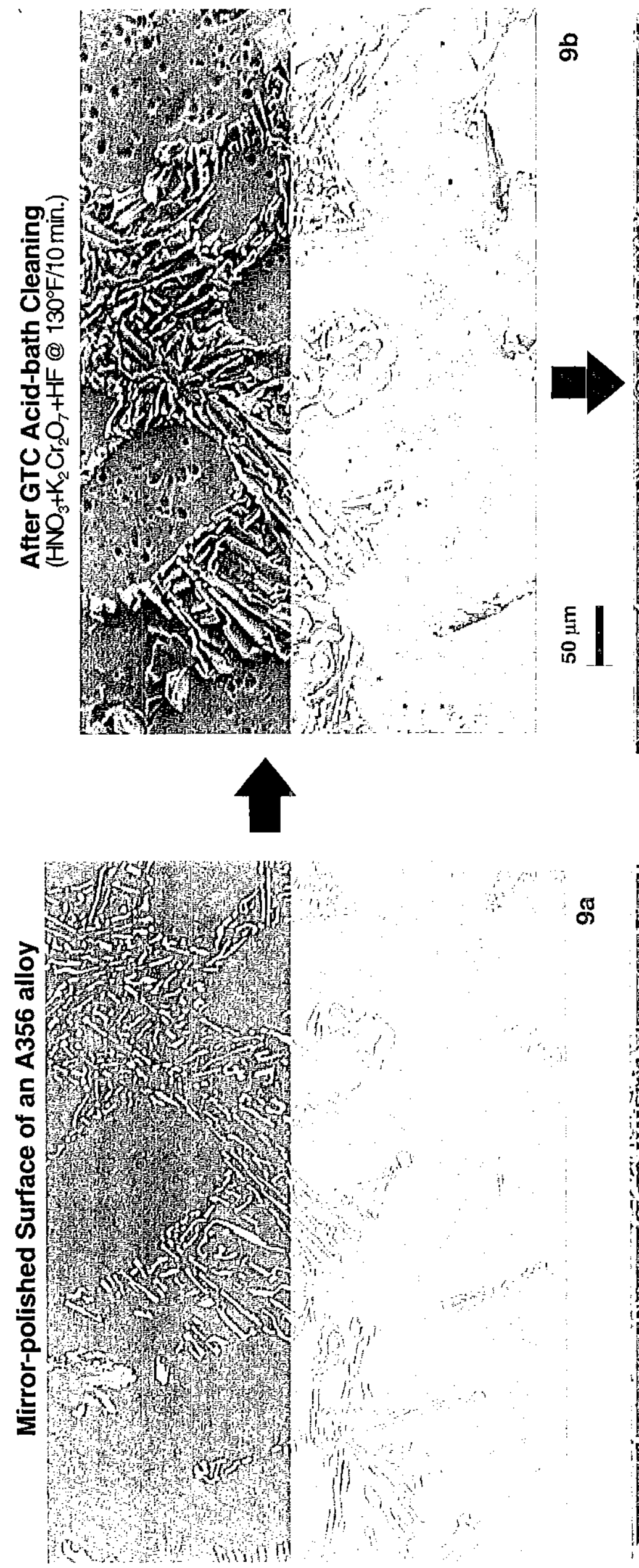

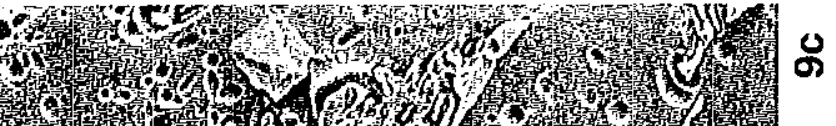
7 I 7.

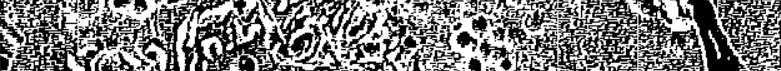

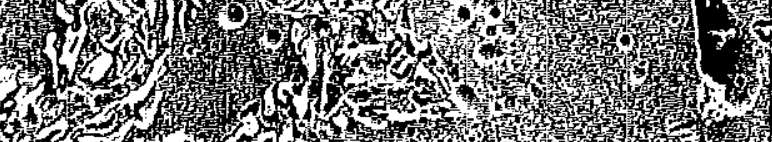

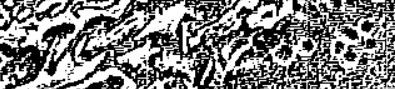

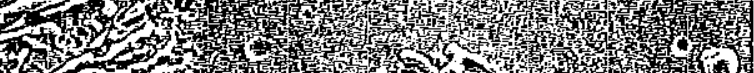

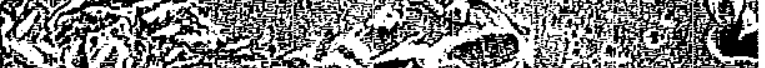

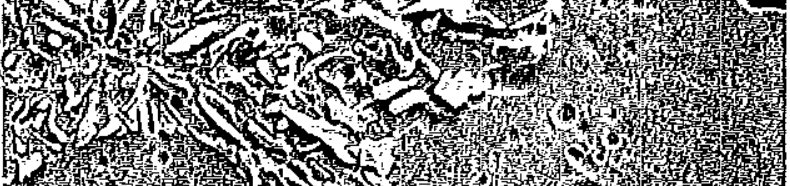

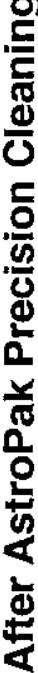

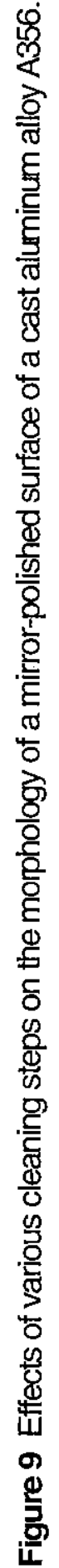
(1)

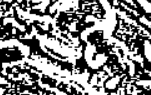

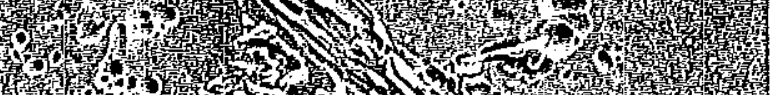
7. 1. 


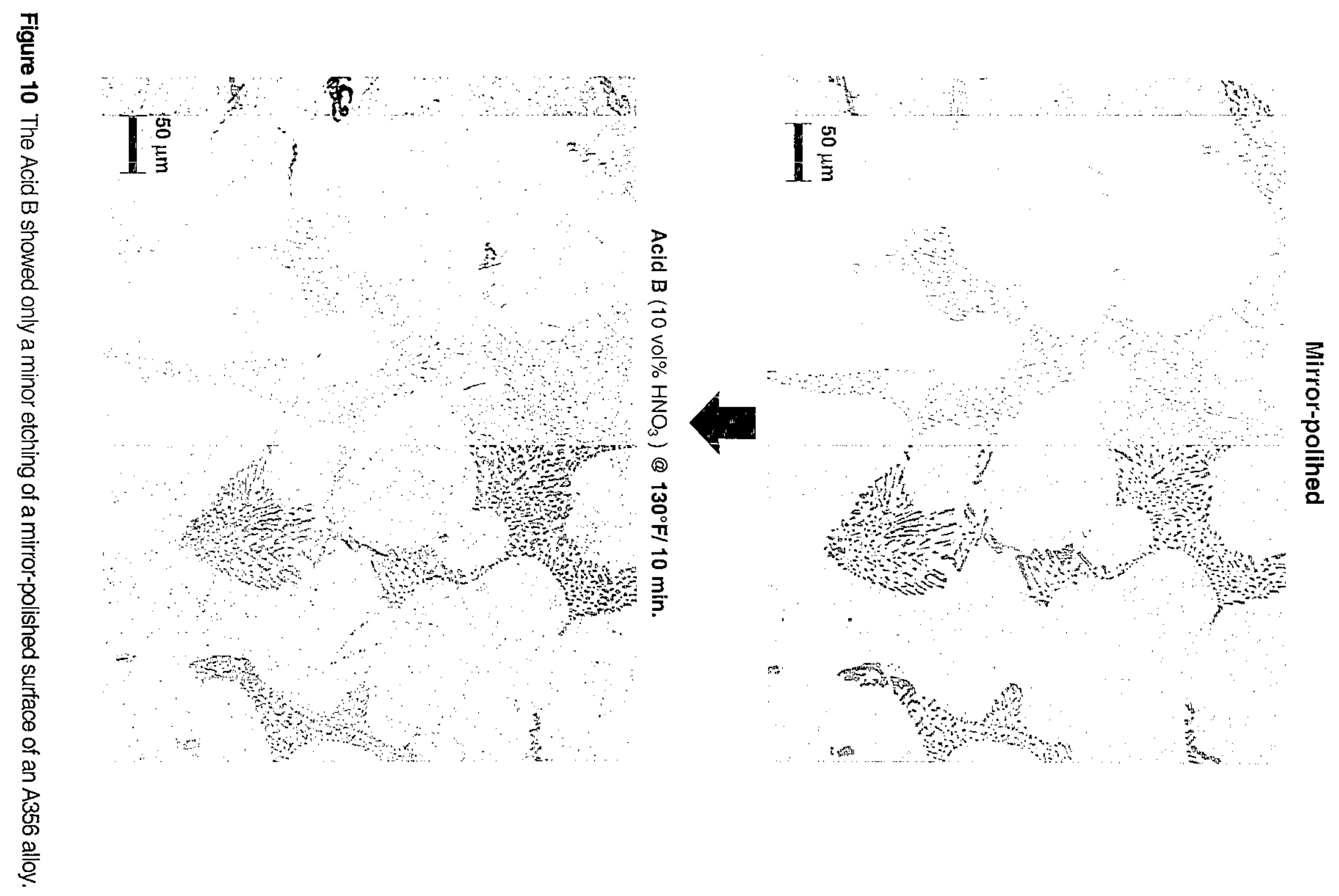




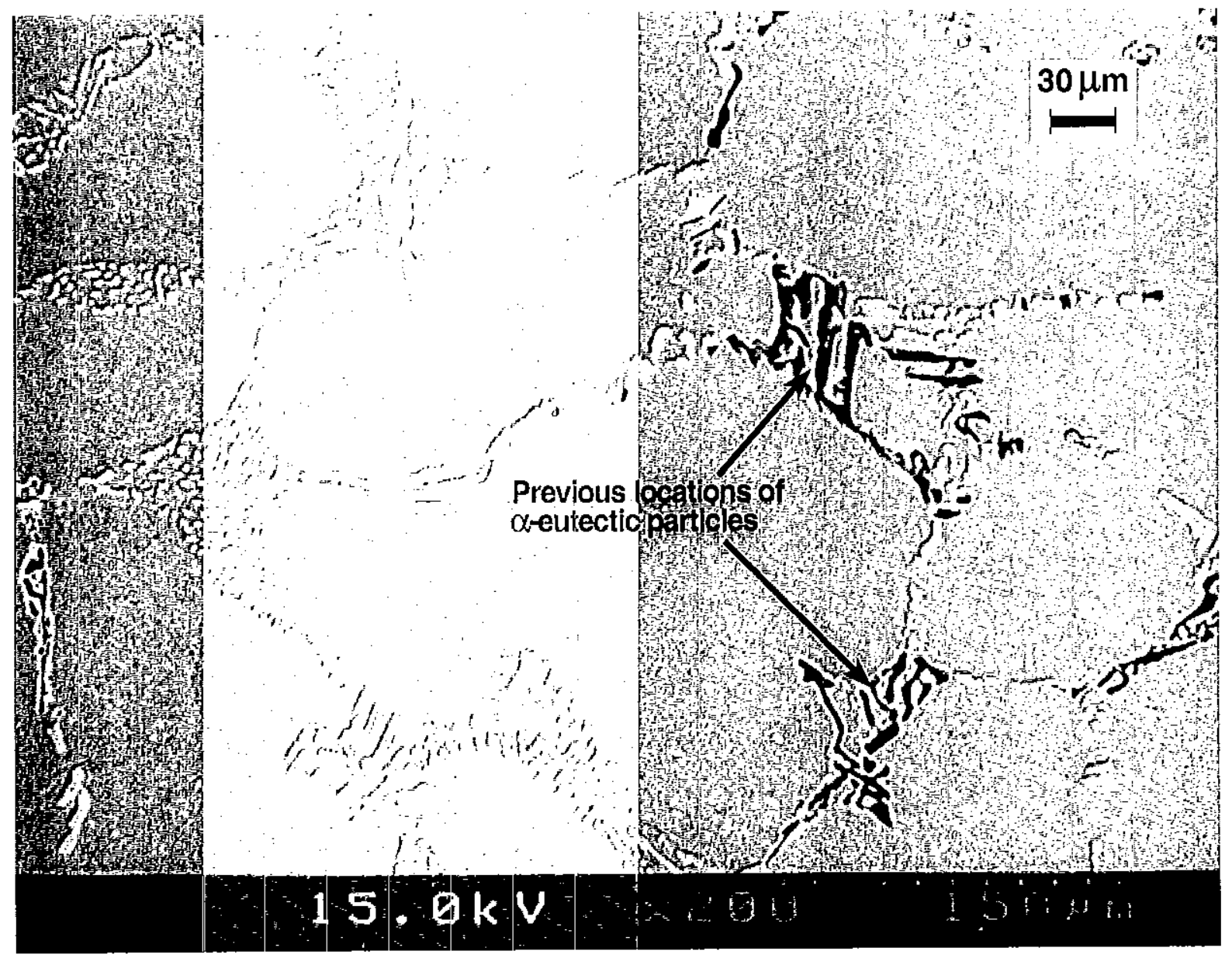

Figure 11 The Acid B etched the $\alpha$-eutectic particles and left behind deep pits. 

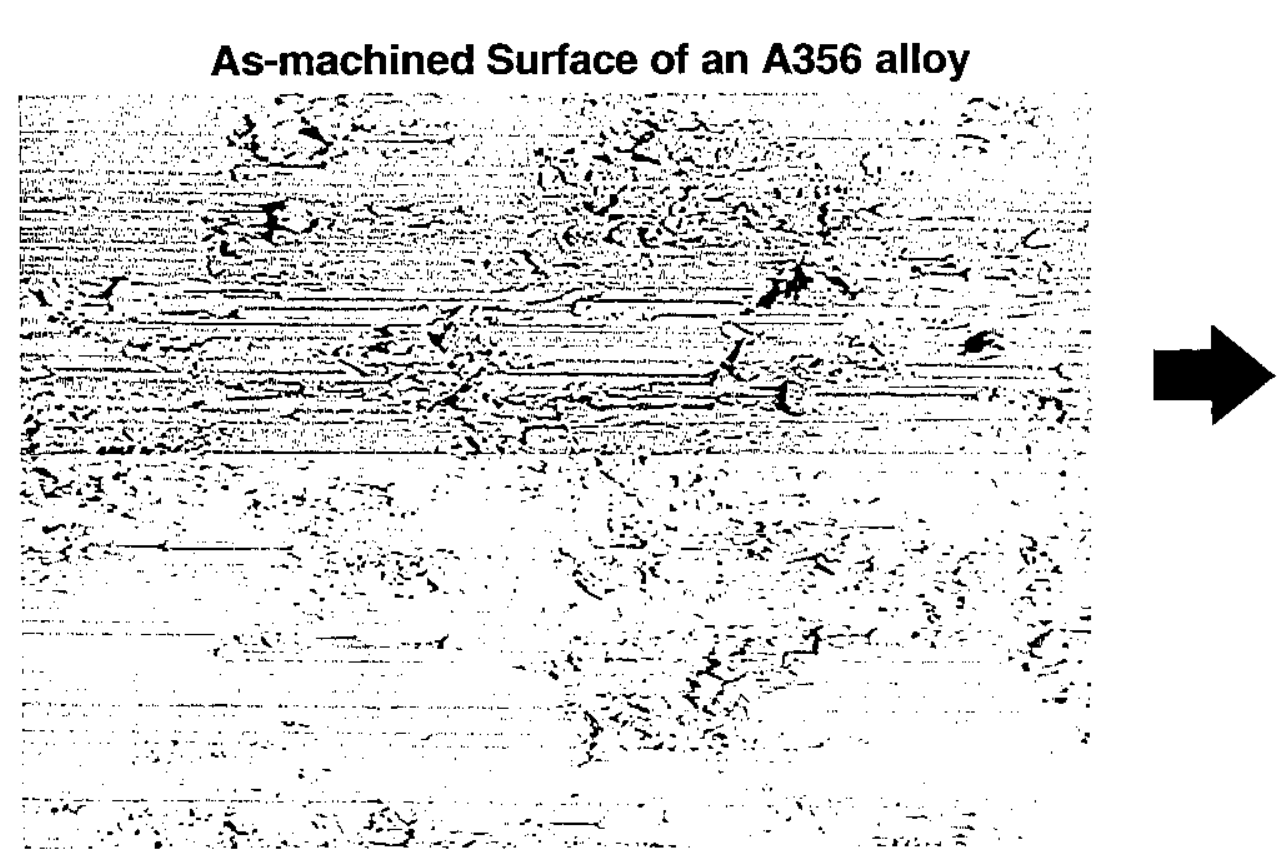

$12 \mathrm{a}$
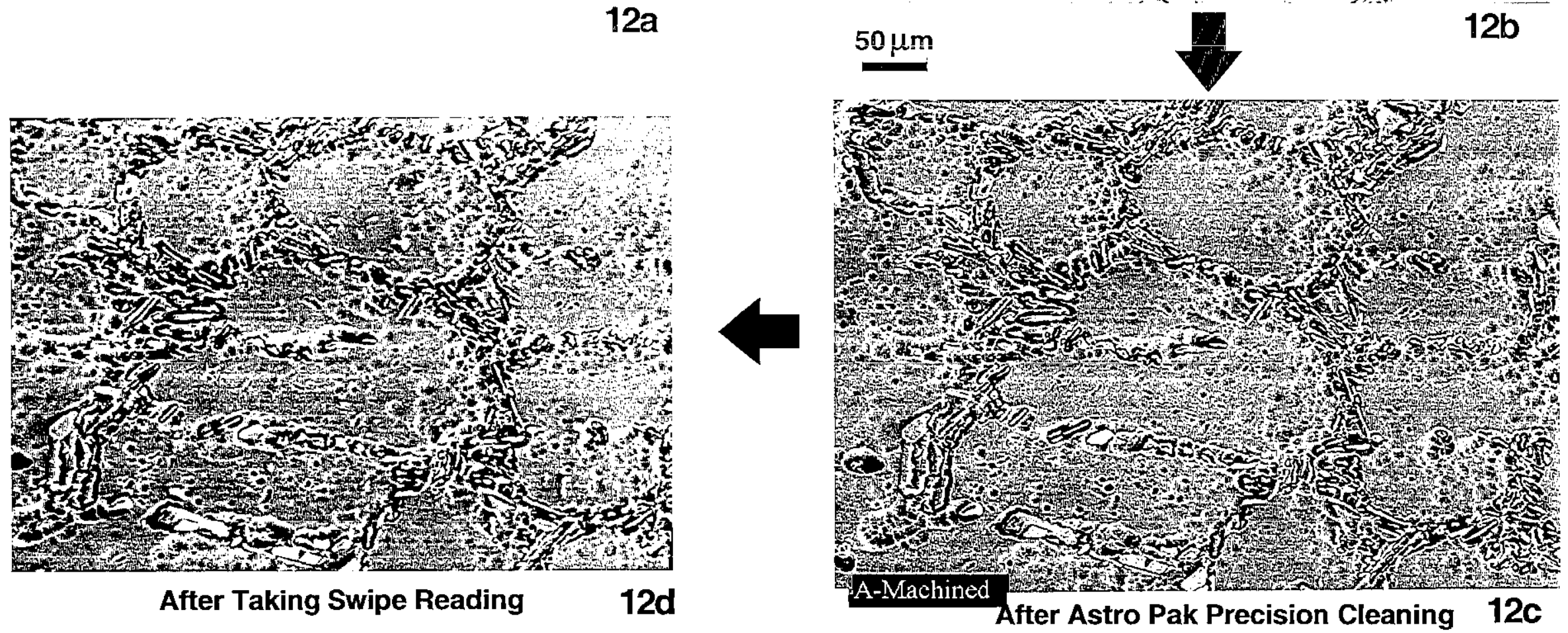

Figure 12 Effects of various cleaning steps on the morphology of an as-machined surface of a cast aluminum alioy A356. 


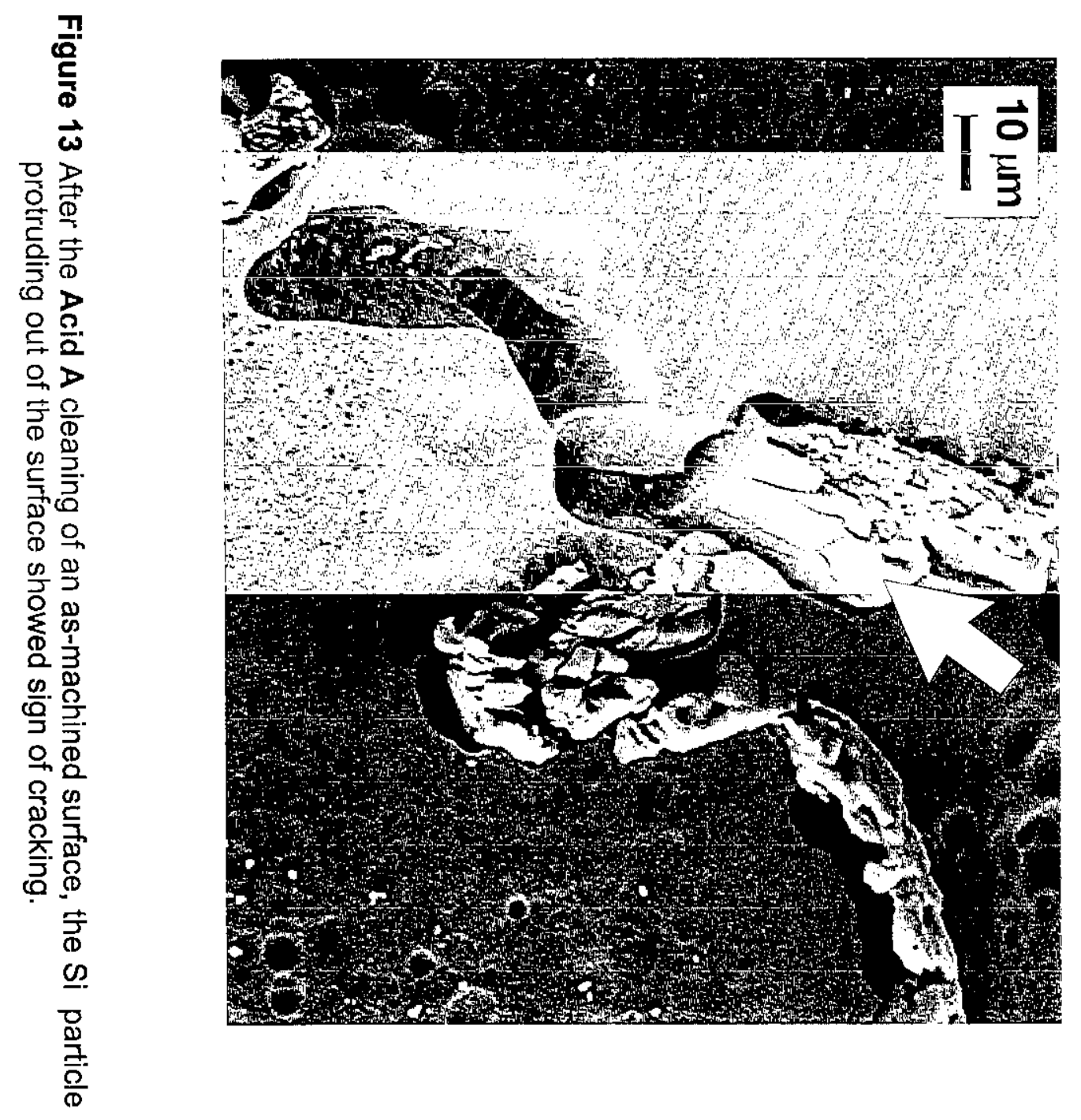




\section{As-machined}
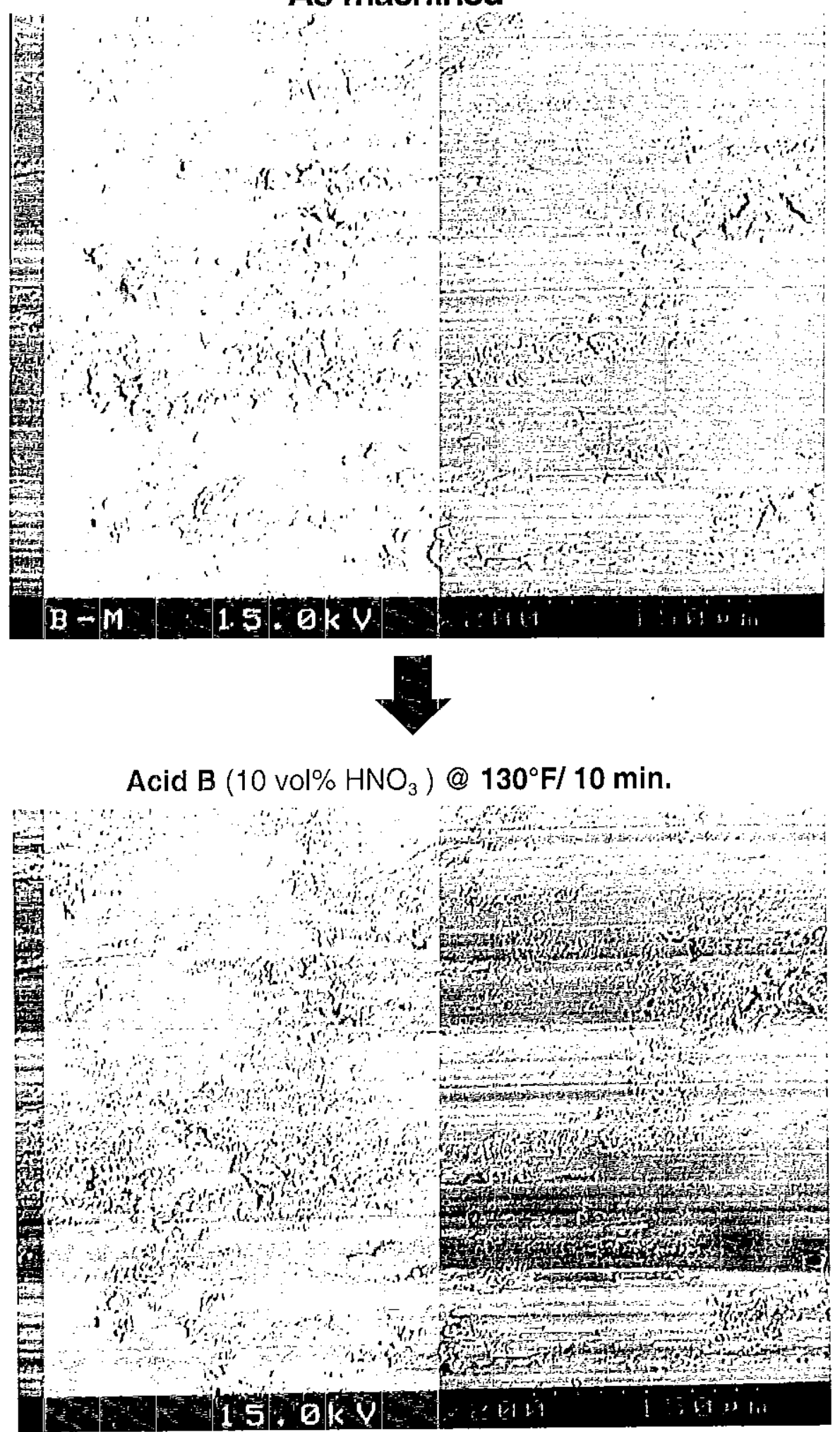

Figure 14 The Acid B showed only a minor etching of the as-machined surface of an A356 alloy. 


\section{Ae rosol Data Comparis on}

Al Plates: TZC-4, TZC-5, TZW-4, TZW-5

Clime t data vs. Shot number

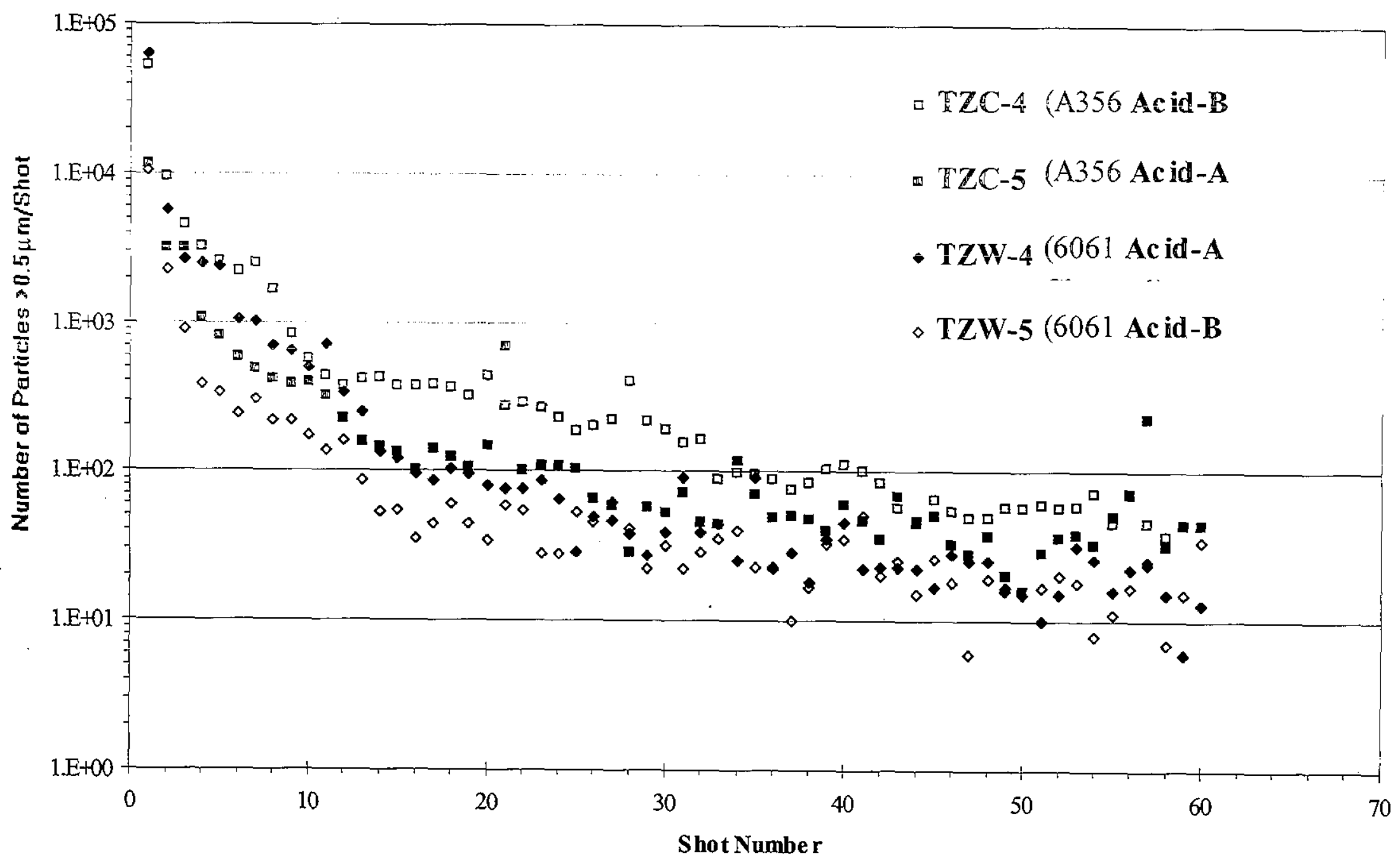

Figure 15 The results of aerosol testing of Acid-A and Acid-B cleaned A356 and 6061 alloys. 
$16 a$

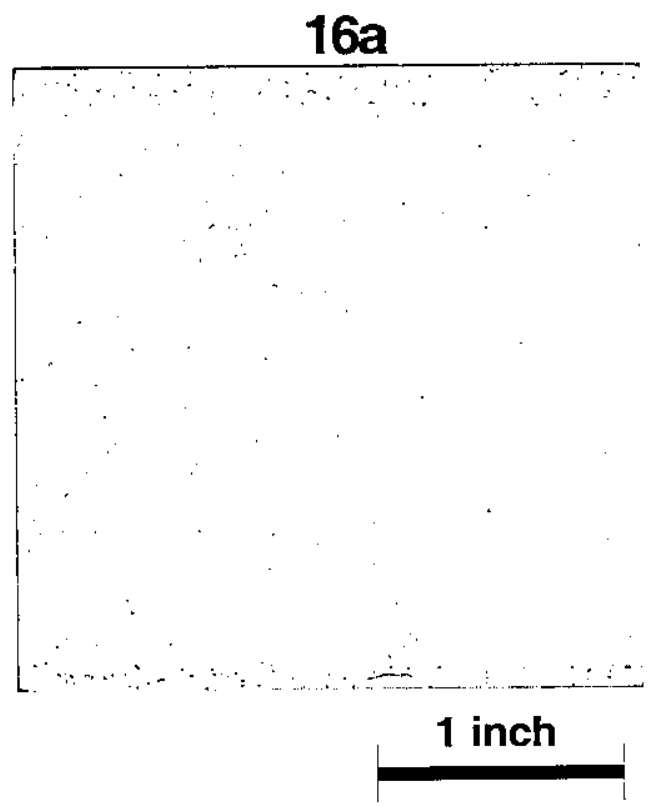

Area Density of Porosity $=186$ per in $^{2}$

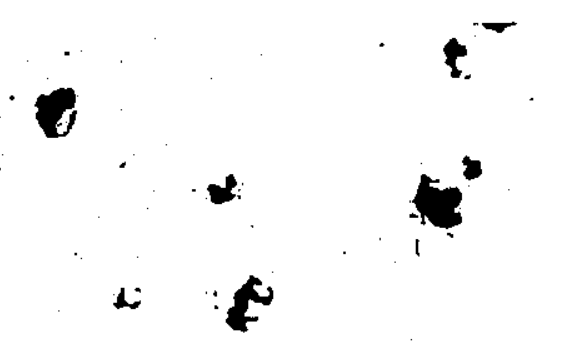

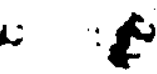

inch

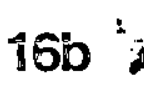

.
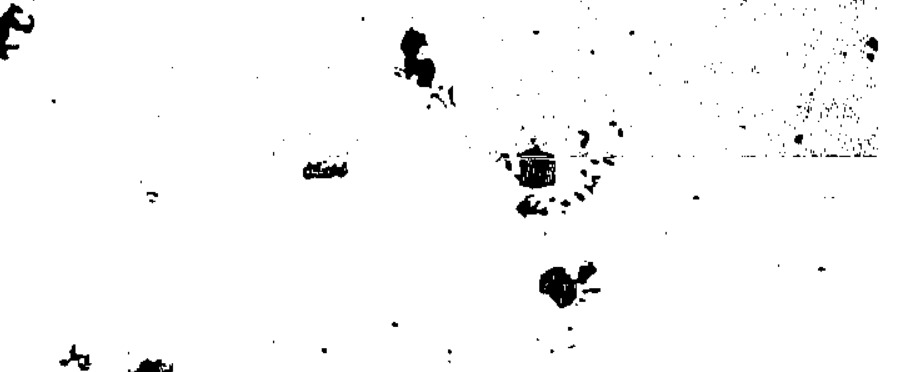

. .

$16 c$

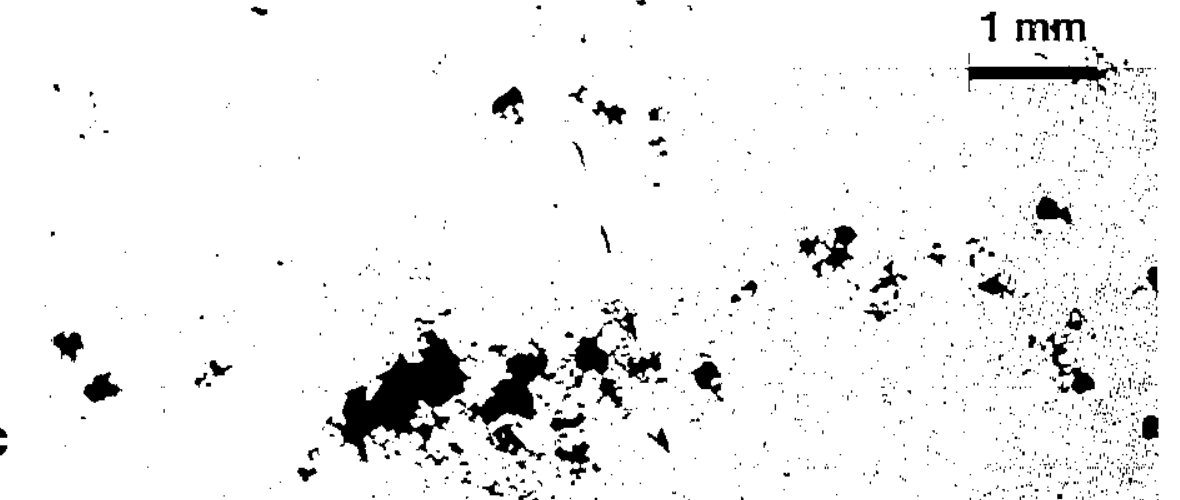

$1 \mathrm{~mm}$

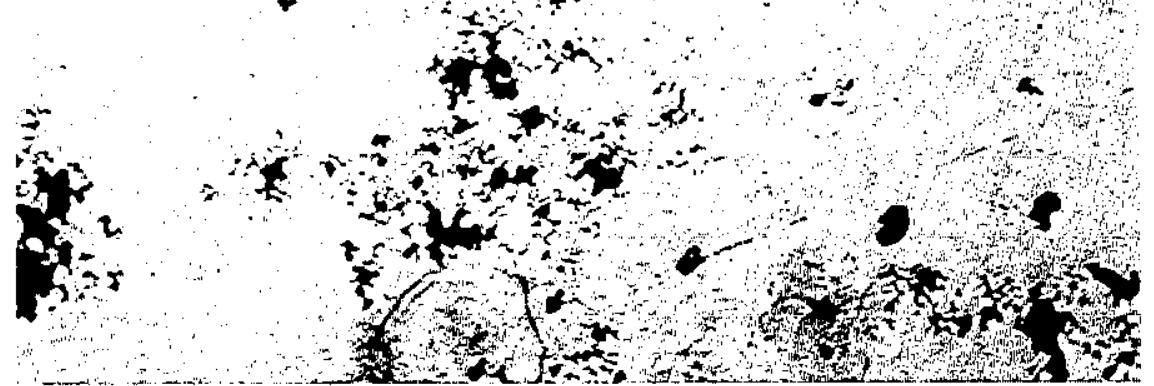

Figure 16 Typical distribution of porosity in cast aluminum alloy A356 of a FAU part. 

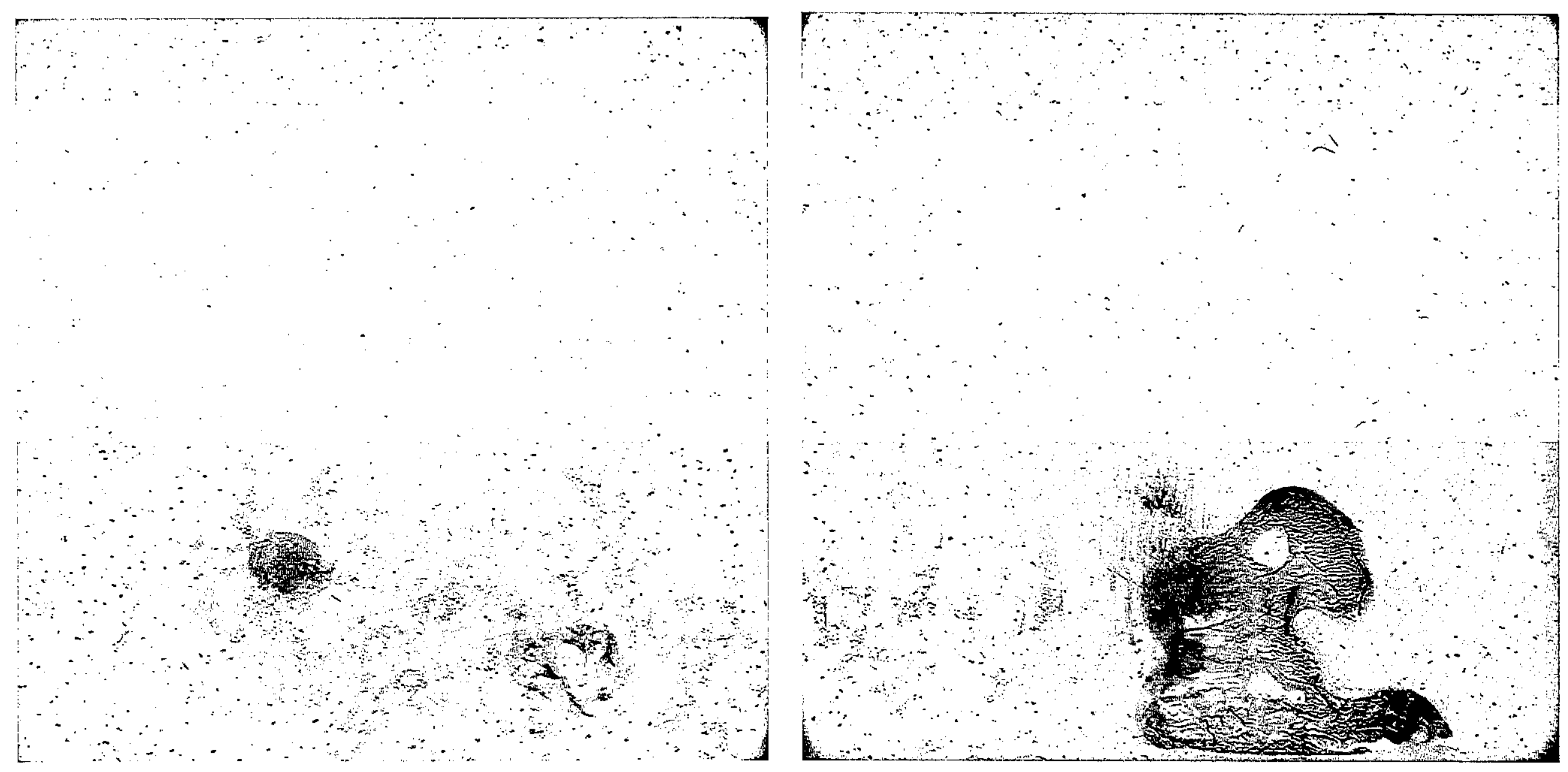

1 inch

Figure 17 The porosities in the sample trapped water which later leached out to the surface during a 24-hour drying period. The staining of the surface is quite evident from the two samples above. 

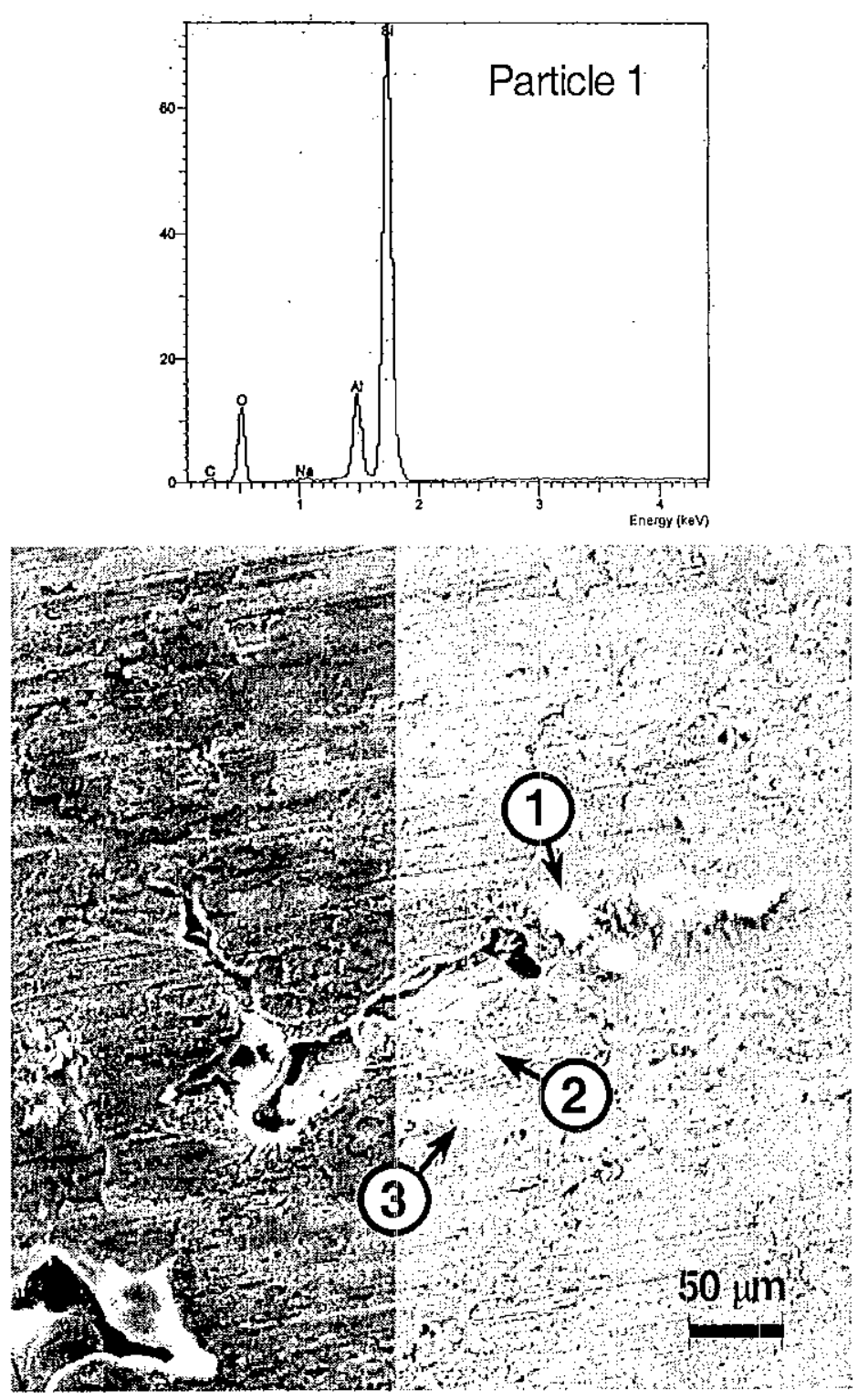

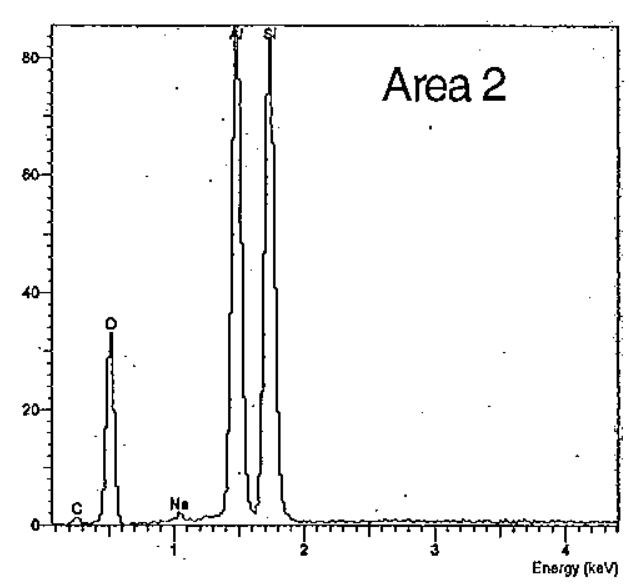

Page 30

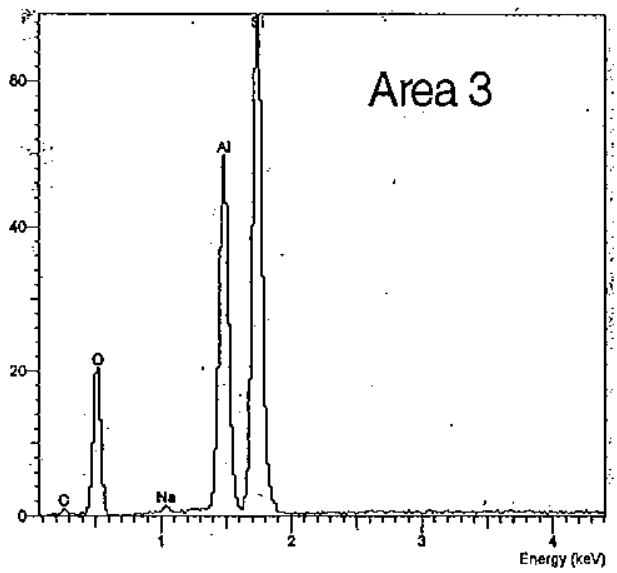

Figure 18 Areas around a cast porosity of an alloy A356 showing the fomation of aluminum hydroxide.
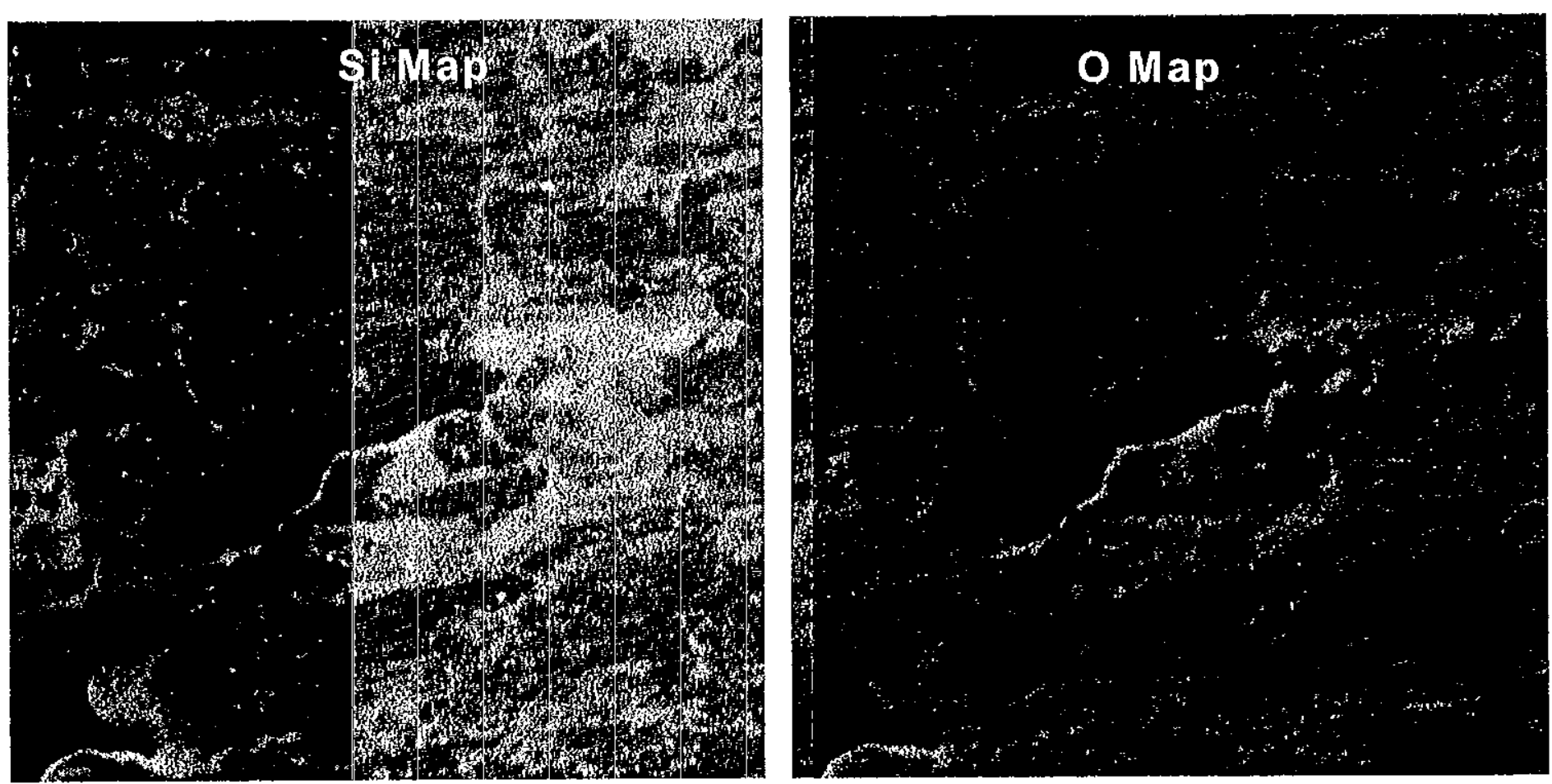


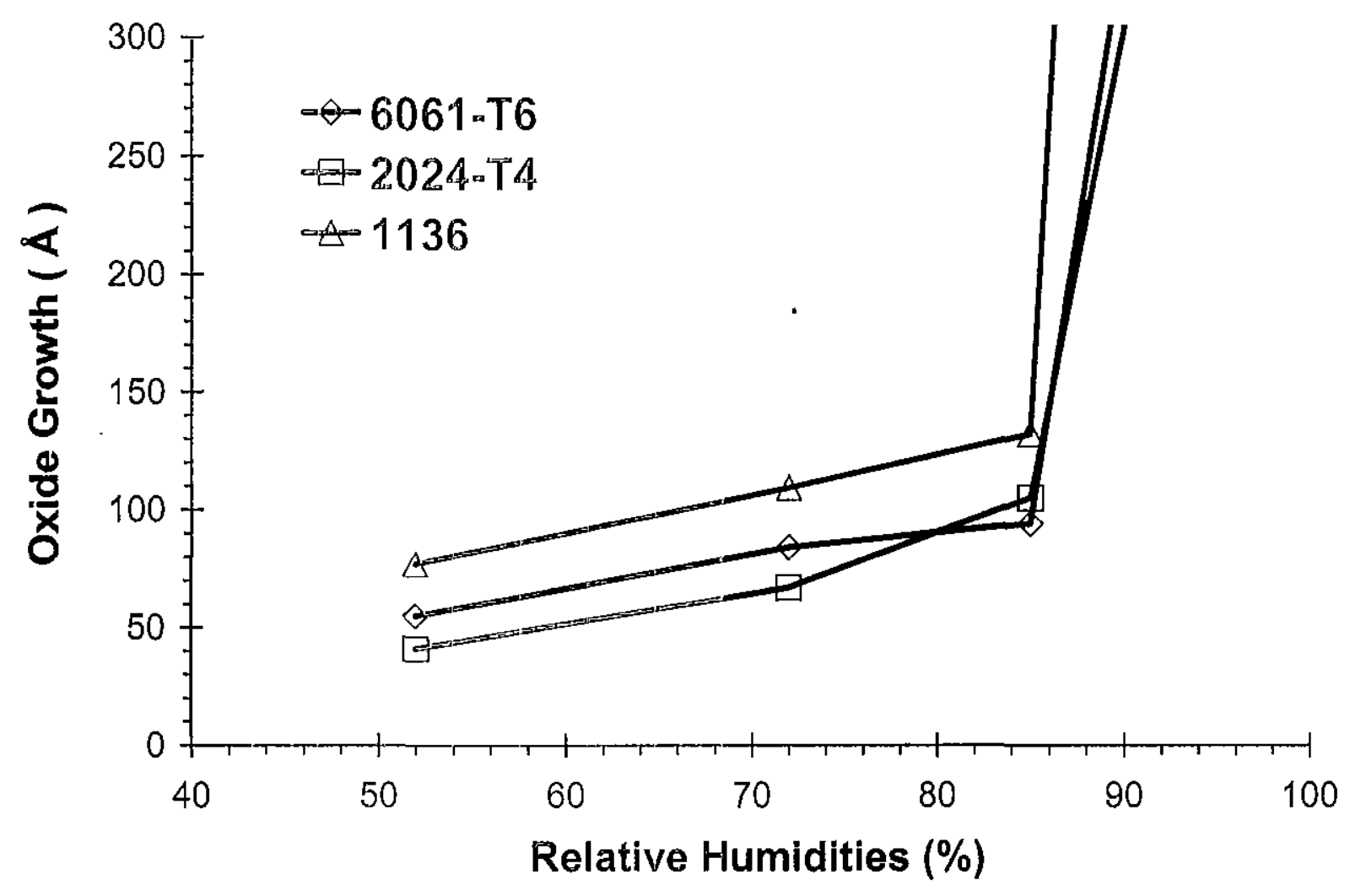

Figure 19 Oxide growth rate of aluminum alloys exposed in air for five years. 


\section{Appendix A-1}

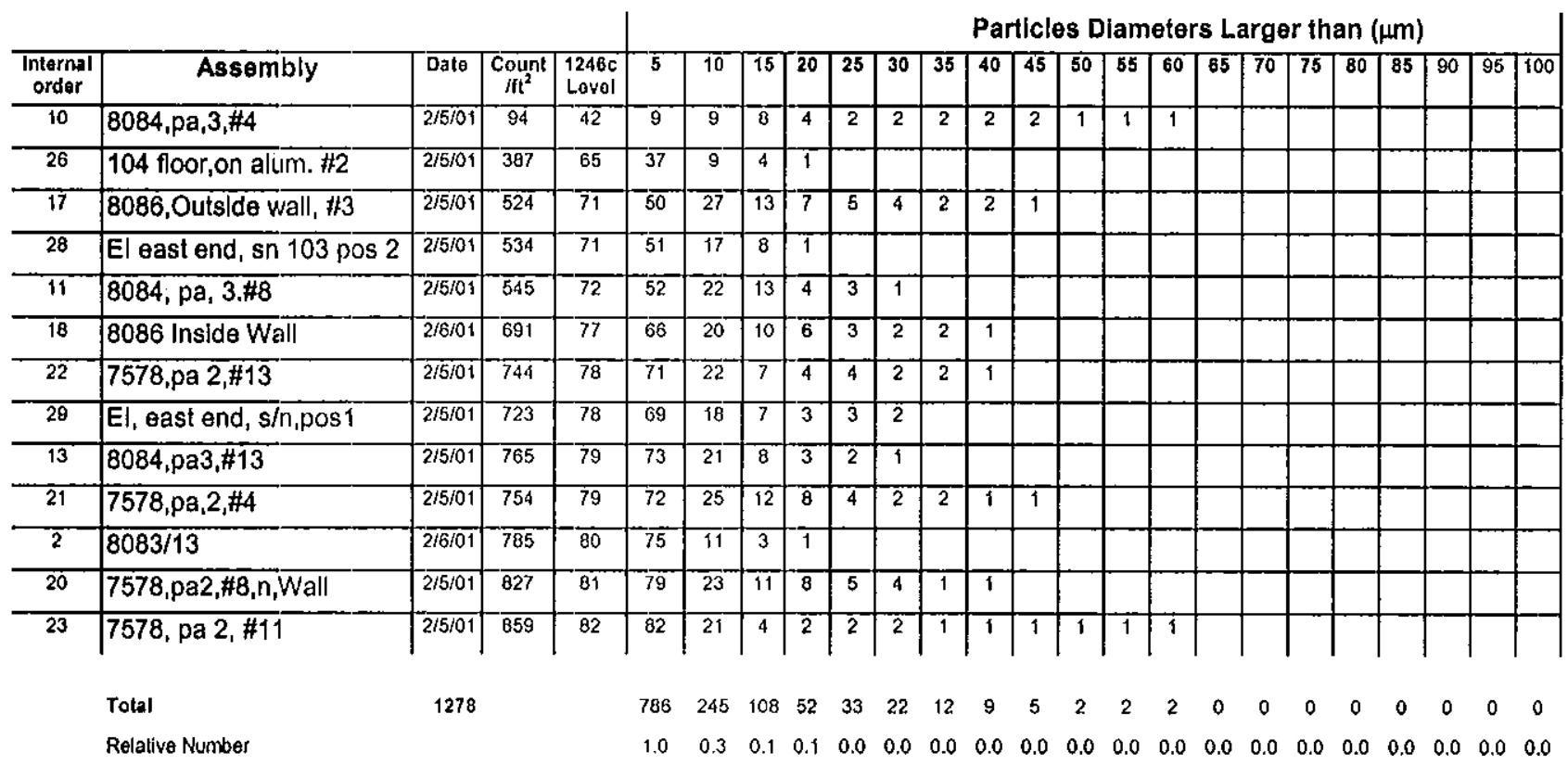

Particle Diameters Larger than $(\mu \mathrm{m})$

\begin{tabular}{|c|c|c|c|c|c|c|c|c|c|c|c|c|c|c|c|c|c|c|c|c|c|c|c|c|}
\hline & & & & & \multicolumn{20}{|c|}{ Particle Diameters Larger than $(\mu \mathrm{m})$} \\
\hline $\begin{array}{l}\text { Internal } \\
\text { order }\end{array}$ & Assembly & Date & $\begin{array}{c}\text { Count } \\
\mathrm{ft}^{2}\end{array}$ & {$\left[\begin{array}{l}\overline{1246 c} \\
\text { Level }\end{array}\right.$} & 5 & 10 & 15 & 20 & 25 & 30 & 35 & 40 & 45 & 50 & 55 & 60 & 65 & 70 & 75 & 80 & 85 & 90 & 95 & 100 \\
\hline 12 & $8084, \mathrm{pa3}, \# 11$ & $215 / 01$ & $\overline{974}$ & 85 & 93 & 37 & 15 & 5 & 3 & 3 & 2 & 2 & $i$ & & & & & & & & & & & \\
\hline 3 & $7490, p a 1, \# 6$ & $2 / 5 / 01$ & 1037 & 86 & 99 & 44 & 25 & 15 & 9 & 5 & 4 & 1 & & & & & & & & & & & & \\
\hline 14 & $8084, p a, 3, \# 14$ & $2 / 5 / 01$ & 1026 & 86 & 98 & 48 & 22 & 8 & 5 & 1 & 1 & & & & & & & & & & & & & \\
\hline 25 & El 104, $s$ wall, on alum \#1 & $2 / 5101$ & 1047 & 86 & 100 & 11 & 4 & $\overline{2}$ & 2 & 2 & 2 & & & & & & & & & & & & & \\
\hline 5 & $7490, \# 2, \mathrm{pa}, 1$, top & $215 / 01$ & 1068 & 87 & 702 & 53 & 27 & $\overline{16}$ & 11 & 7 & 3 & 2 & 2 & 2 & 2 & 2 & 2 & 1 & 1 & 1 & 1 & 1 & 1 & \\
\hline 6 & $7490, p_{1}, 1, \# 8$ & $2 / 5101$ & 1079 & 87 & 103 & 47 & $\overline{16}$ & $\overline{11}$ & 6 & 3 & 2 & 2 & 2 & 2 & 1 & 1 & 1 & $T$ & $T$ & & & & & \\
\hline 7 & $7490, p a, 1, \# 14$ & $2 / 5 / 01$ & \begin{tabular}{|l|l}
1110 \\
\end{tabular} & $8 \bar{\theta}$ & $70 \overline{6}$ & 12 & 7 & 3 & 3 & 1 & 1 & 1 & 1 & 1 & & & & & & & & & & \\
\hline$\overline{16}$ & $\begin{array}{l}8086 \text { angle Reference } \\
\text { outside \#2 }\end{array}$ & $2 / 5 / 01$ & 1236 & 90 & $\overline{118}$ & 31 & 8 & 4 & 2 & 2 & 1 & 1 & 1 & 1 & $T$ & 1 & & & & & & & & \\
\hline 27 & 104 , s wall \#3 & $215 / 01$ & 1320 & $\overline{92}$ & 126 & 37 & 15 & 8 & 6 & 5 & 1 & 1 & & & & & & & & & & & & \\
\hline 30 & El in & $215 / 01$ & 1330 & 92 & 127 & 32 & 16 & 8 & 6 & 6 & 3 & 2 & 1 & 7 & & & & & & & & & & \\
\hline 8 & 7490 Inslde Corner Wall & $2 / 6 / 01$ & 1361 & $\overline{93}$ & 130 & $\overline{14}$ & 8 & 4 & 2 & 2 & 2 & 2 & 1 & & & & & & & & & & & \\
\hline 4 & 7490, pa1,\#4 & $2 / 5101$ & \begin{tabular}{|l|}
1539 \\
\end{tabular} & 96 & 147 & 73 & $\overline{40}$ & 26 & 22 & 16 & 10 & 7 & 5 & 2 & 1 & 1 & & & & & & & & \\
\hline 19 & 8086 Inside lower casting & $216 / 101$ & 1728 & 99 & 165 & 19 & 5 & $-\overline{3}$ & 2 & 1 & 1 & 7 & 1 & & & & & & & & & & & \\
\hline 32 & El Inside faclng East & $2 / 5 / 01$ & 2650 & 111 & 253 & 300 & 15 & 5 & 2 & 1 & 1 & & & & & & & & & & & & & \\
\hline 31 & El Inside Top & $2 / 5101$ & 3142 & 116 & 300 & 55 & $\overline{24}$ & \begin{tabular}{|l|}
12 \\
\end{tabular} & 7 & 5 & & & & & & & & & & & & & & \\
\hline 15 & $\begin{array}{l}\text { 8086,inside lower } \\
\text { wall/Port Side }\end{array}$ & $2 / 5 / 01$ & 3194 & 117 & 305 & 72 & 22 & 10 & 4 & 3 & 3 & 2 & & & & & & & & & & & & \\
\hline 24 & 7578, pa $2, \# 14$ & $2 / 5 / 101$ & 3330 & 118 & 318 & 38 & 11 & $\overline{6}$ & 3 & 2 & 2 & 2 & 2 & 2 & & & & & & & & & & \\
\hline 9 & $7490, \mathrm{pa}_{1} 1, \# 11$ & $2 / 2 / 5 / 01$ & 7551 & 145 & 721 & 34 & 11 & 3 & 2 & 2 & 1 & & & & & & & & & & & & & \\
\hline 1 & 8083 & $226 / 61$ & \begin{tabular}{|l|}
9373 \\
\end{tabular} & 153 & 895 & 44 & 8 & 3 & 3 & 3 & & & & & & & & & & & & & & \\
\hline & Total & 6043 & & & 4306 & 1001 & 299 & 152 & 100 & 70 & 40 & 26 & 17 & 11 & 5 & 5 & 3 & 2 & 2 & 1 & 1 & 1 & 1 & \\
\hline & Relealive Number & & & & 1.00 & 0.23 & 0.1 & 0.0 & 0.0 & 0.0 & 0.0 & 0.0 & 0.0 & 0.0 & 0.0 & 0.0 & 0.0 & 0.0 & 0.0 & 0.0 & 0.0 & 0.0 & 0.0 & 0.0 \\
\hline
\end{tabular}




\section{APPENDIX A-2}

\begin{tabular}{|c|c|c|c|c|c|c|c|c|c|c|c|c|c|c|c|c|c|c|}
\hline & & & & & & \multicolumn{13}{|c|}{ X-ray Counts } \\
\hline Sample & $\operatorname{Tim} \theta$ & Part/ Swipo & Unit & Alloy & Size & C & 0 & $\mathrm{Mg}$ & Al & SI & $s$ & C) & $K$ & $\mathrm{Ca}$ & Ti & $\mathrm{Cr}$ & $F_{\theta}$ & NI \\
\hline 5687 & $10: 31$ & MA3 $\$ 19$ L 103 & FAU & A356 & & & & & & 1300 & & & & & & & & \\
\hline 5687 & $10: 34$ & MA3 $\$ 9$ L 103 & $\overline{\mathrm{FAU}}$ & $\overline{A 356}$ & & $1 \overline{60}$ & 15 & & & & & & & 5 & 5 & & & \\
\hline 5687 & $10: 45$ & MA3 $\# 9$ L 103 & FAU & A356 & & 10 & 5 & & & 90 & & & & & & & & \\
\hline 5687 & $14: 05$ & $\mathrm{MA} 3-\mathrm{C}$ & FAU & A356 & & 4 & 5 & & & & & & & 21 & & & & \\
\hline 5687 & $14: 14$ & MA3-C & $\mathrm{FAU}$ & A356 & & 4 & $\frac{\pi}{1}$ & & & & & 3 & & $\frac{4}{2}$ & 3 & & & \\
\hline 5687 & $14: 22$ & $M A 3-C$ & $\mathrm{FAU}$ & A356 & & & & & & & & & & 30 & & & & \\
\hline 5687 & $14: 35$ & MA $3-C$ & $\mathrm{FAU}$ & $\overline{\mathrm{A}} 356$ & & 6 & 1 & & & 1 & & 1 & & 1 & 2 & & & \\
\hline & & & & & & & & & & & & & & & & & & \\
\hline 5695 & $14: 28$ & $\# 15$ & FAU & A356 & $4 \mu \mathrm{m}$ & 1 & 1 & & 1 & 250 & & & & & & & & \\
\hline 5695 & $16: 10$ & $\# 15$ & $\overrightarrow{\mathrm{FAU}}$ & A356 & $4 \mu \mathrm{m}$ & 1 & 1 & & 1 & 0.5 & & & & & & 5 & & \\
\hline 5695 & $16: 19$ & $\# 16$ & FAU & $\overline{\mathrm{A}} 356$ & $4 \mu \mathrm{m}$ & 4 & 4 & & 2 & 16 & & & & 64 & & & & \\
\hline 5695 & $11: 07$ & $\mathrm{Pal} \widehat{\mathrm{C4} 15}$ & $\mathrm{FAU}$ & $\overline{A 356}$ & $3 \mu \mathrm{m}$ & 30 & 15 & & 10 & 300 & & & & & & & & \\
\hline 5695 & $11: 42$ & Pal C4 15 & FAU & A356 & $2 \mathrm{um}$ & 30 & 15 & & 5 & 300 & & & & & & & & \\
\hline 5695 & $11: 45$ & Pal C415 & $\overline{\mathrm{FAU}}$ & A356 & $1 \mu \mathrm{m}$ & 35 & 20 & & 5 & 300 & & & & & & & & \\
\hline 5695 & $11: 46$ & $\mathrm{Pal} \overline{\mathrm{C}} 415$ & $\mathrm{FAU}$ & A356 & & 26 & 19 & & 1 & 1 & & & & & & & & \\
\hline 5695 & $12: 14$ & $\mathrm{Pal} \mathrm{C} 416$ & FAU & A356 & & 5 & 4 & & 3 & & & & & & & & & \\
\hline 5695 & $12: 17$ & $\mathrm{Pal} \mathrm{C} 416$ & $\mathrm{FAU}$ & A356 & $2000 \mu \mathrm{m}$ & 12 & 8 & & 0.5 & 3.20 & & & & & & & & \\
\hline 5695 & $12: 22$ & Pal $\mathrm{C} 416$ & & & & 11 & 6 & & 2 & 20 & & & & & & & & \\
\hline & & & & & & & & & & & & & & & & & & \\
\hline 5691 & $14: 35$ & S/N $102 \mathrm{M}-5 \mathrm{MA} 5$ & $\overline{\mathrm{FAU}}$ & $\overline{\mathrm{A} 356}$ & & 23 & 16 & & 1 & & & & & & & & & \\
\hline 5691 & $13: 56$ & $\mathrm{~S} / \mathrm{N} 102 \mathrm{M}-5 \mathrm{MA} 5$ & $\mathrm{FAU}$ & A356 & $1-3 \mathrm{um}$ & 18 & 14 & & 2 & 14 & & & & & & & & \\
\hline 5691 & $13: 30$ & S/N $102 \mathrm{M}-5 \mathrm{MA} 5$ & FAU & A356 & $5 \mu \mathrm{m}$ & 10 & 8 & & 5 & 260 & & & & & & & & \\
\hline 5691 & $13: 33$ & $\mathrm{~S} / \mathrm{N} 102 \mathrm{M}-5 \mathrm{MA} 5$ & FAU & A356 & $4 \mu \mathrm{m}$ & 19 & 5 & & 3 & 50 & & 3 & & 4 & 4 & & & \\
\hline 5691 & $13: 48$ & $S / N 102 M-5$ MAS & $\overline{\mathrm{FAU}}$ & $\overline{A 356}$ & & 10 & 8 & & 1 & 55 & & & & & & & & \\
\hline
\end{tabular}

\begin{tabular}{|c|c|c|c|c|c|c|c|c|c|c|c|c|c|c|c|c|c|c|}
\hline & & & & & & \multicolumn{13}{|c|}{ X-ray Counts } \\
\hline Sample & Time & Part/Swipe & Unit & Alloy & Size & $\mathrm{c}$ & 0 & $\mathrm{Mg}$ & $\overline{A l}$ & SI & $\mathbf{s}$ & $\mathrm{Cl}$ & $\mathrm{K}$ & $\mathrm{Ca}$ & $\mathrm{TI}$ & $\mathrm{Cr}$ & $\mathrm{Fe}$ & $\mathbf{N I}$ \\
\hline 5690 & $13: 45$ & $\mathrm{~S} / \mathrm{N} 104 \mathrm{H} 3$ & $\bar{E} \mid \bar{A}$ & 6061 & & 160 & 20 & & & & & & & & & & & \\
\hline 5690 & $13: 48$ & $\mathrm{~S} / \mathrm{N} 104$ 栘 3 & EIA & 6061 & & 8 & 4 & & & & & & & & & & 2 & \\
\hline 5690 & $13: 52$ & $\widehat{S / N} 104+13$ & $E \mid \bar{A}$ & 6061 & & 17 & 16 & & & & & & & & & & 1 & \\
\hline 5690 & $13: 55$ & $S / N 104+33$ & $E \mid A$ & 6061 & & 5 & 5 & & & & & & & & & 20 & 62 & 5 \\
\hline 5690 & $13: 57$ & S/N 104 政3 & $E \mid A$ & 6061 & & 6 & 3 & & & & & & & & & & 1 & \\
\hline 5690 & $13: 59$ & S/N $104 \$ 3$ & हाA & 6061 & & 5 & 4 & & & & & & & & & 20 & 60 & 5 \\
\hline 5690 & $14: 02$ & $S / N 104$ 极 3 & EIA & 6061 & & 4 & 2 & & & & & & & & & $\mathrm{~T}$ & 1 & $T$ \\
\hline 5690 & $14: 27$ & $S / N 104 \$ 3$ & EIA & 6061 & $<1 \mu \mathrm{m}$ & 3 & 2 & & & & & & & & & 5 & 15 & 2 \\
\hline 5690 & $9: 41$ & $\mathrm{~S} / \mathrm{N} 104 \mathrm{~N} 1$ & $E \mid A$ & 6061 & & 20 & 10 & & & & & & & & & 20 & 60 & 5 \\
\hline 5690 & $9: 43$ & $S / N 104$ H1 & $E \mid \mathrm{A}$ & 6061 & & 14 & 8 & & & & & & & & & 10 & 25 & 3 \\
\hline 5690 & $9: 47$ & S/N 104 林1 & $\overline{E \mid A}$ & 6061 & & 7 & 4 & & & & & & & & & 1 & 3 & $\mathrm{~T}$ \\
\hline 5690 & $10: 32$ & S/N $104 \# 1$ & $\overline{E I A}$ & 6061 & & 4 & 2 & & & & & & & & & 8 & 25 & 3 \\
\hline 5690 & $10: 33$ & $S / N 104$ \# 1 & $E \mid A$ & 6061 & $1 \mu \mathrm{m}$ & 2 & 1 & & & & & & & & & 5 & 15 & 1 \\
\hline 5690 & $10: 36$ & $S / N 104$ & EIA & 6061 & $1.5 \mu \mathrm{m}$ & 4 & 2 & & & & & & & & & 4 & 12 & 1 \\
\hline 5690 & $10: 39$ & $\mathrm{~S} / \mathrm{N} 104 \mathrm{\# 1}$ & EIA & 6061 & $1.2 \mu \mathrm{m}$ & 8 & 3 & & & & & & & & & 4 & 12 & 1 \\
\hline 5690 & $13: 06$ & $S / N 104 \# 1$ & $E \mid A$ & 6061 & $1 \mu \mathrm{m}$ & 30 & 15 & & & & & & & & & 30 & 85 & 10 \\
\hline 5697 & $13: 46$ & $S / N 104$ \#1 & $E \mid \bar{A}$ & 6061 & $1.5 \mu \mathrm{m}$ & 0.8 & 1 & 1 & 4 & & & & & & 4 & & & \\
\hline 5697 & $13: 51$ & $\bar{S} / N 104$ 相 & $E \mid A$ & 6061 & $1.0 \mu \mathrm{m}$ & 1.2 & 1 & & 2 & & & & & & 6 & 0.6 & 0.6 & \\
\hline 5697 & $13: 58$ & $\widehat{S} / \mathrm{N} 104$ 列 & EIA & 6061 & $3.0 \mu \mathrm{m}$ & 2 & 3 & & 27 & & & & & & 2 & 2 & 1 & \\
\hline 5697 & $14: 05$ & $\mathrm{~S} / \mathrm{N} 104 \# 1$ & $E \mid A$ & 6061 & $1.0 \mu \mathrm{m}$ & 1 & 1 & & 2 & & & & & & 17 & 2 & 1 & \\
\hline 5697 & $14: 12$ & S/N 104 \#1 & $E \mid A$ & 6061 & $2.0 \mu \mathrm{m}$ & 6 & 17 & 16 & 22 & & & & & & 1 & 2 & & \\
\hline 5697 & $14: 15$ & $S / N 104 \# 1$ & $E \mid A$ & 6061 & $4 \mu \mathrm{m}$ & 40 & 25 & 23 & 38 & & & & & & 2 & 1 & & \\
\hline 5697 & $14: 15$ & $S / N 104 \# 1$ & $\overline{E I A}$ & 6061 & $1 \mu \mathrm{m}$ & 8 & 25 & 23 & 38 & & & & & & 3 & 2 & & \\
\hline 5697 & $14: 18$ & S/N 104 \#1 & EIA & 6061 & $1.5 \mu \mathrm{m}$ & 4 & 9 & & & & & & & & $T$ & $T$ & & \\
\hline 5697 & $14: 43$ & $S / N 104 \# 1$ & $E \mid A$ & 6061 & $2.0 \mu \mathrm{m}$ & 20 & 50 & & & & & & & & 2 & $\mathrm{~T}$ & & \\
\hline 5697 & $14: 46$ & $\mathrm{~S} / \mathrm{N} 104 \$ 1$ & $E \mid A$ & 6061 & $2 \mu \mathrm{m}$ & 9 & 6 & & 2 & & & & & & & 12 & 35 & \\
\hline
\end{tabular}




\section{APPENDIX A-3 \\ ASTROPAK REVISION D PROCEDURE}

MARCH 1,2001

1. Identify the frame to be used and document the number in the above location.

2. Uncrate the frame, remove all data and deliver to the Program Manager.

3. Remove all wrapping from frame and perform a visual inspection looking for any anomalies. Report any such findings to the Program Manager.

4. Transfer the Frame to a S.S. $2 \times 2$ pallet.

5. Perform two Brulin/Rinse cycles on the entire frame.

6. Pull 2 NVR samples in locations A and B.

7. Lay the frame down and perform two Zonyl/rinse cycles on the top casting and sidewalls

8. Dry off with N2-

9. Stand the frame up in the vertical position and perform two Zonyl/rinse cycles on the lower casting.

10. Dry off with N2-

11. Perform-n all 16 particle swipes.

12. Remove the frame from the cleanroom and perform a complete "pre-clean" on the entire frame by first cleaning with acetone followed by I 00\% IPA (Reference MEL98-002-OD and MEL98-003-OC). Document the visible marks and iterations below on both the upper and lower castings as well as the sidewalls.

13. Perform particle swipes on locations $9,10,11,12,13$ and 14 . (Note: At this time we will let the frame sit for a minimum of $12 \mathrm{hrs}$. )

14. Repeat step \# 13. Notify the Program Manager of your findings on the wipes before continuing forward.

15. Perform particle swipes on locations $9,10,11,12,13$ and 14 .

(Note: The Program Manager will make a decision at this point to either let the frame sit for an additional $12 \mathrm{hrs}$ or proceed forward. If the decision is made to let the frame sit perform steps 16 and 17. If not, proceed to step 18.)

16. Repeat step \# 13.

17. Perform particle swipes on locations $9,10,11,12,13$ and 14 .

18. Transfer the frame into the cleanroom for precision cleaning

19. Perform two Brulin/rinse cycles on entire frame,

20. Dry off and perform two NVR's in locations A and B.

21. Lay the frame down and perform two Zonyl/rinse cycles on the top rating and sidewalls.

22. Dry off with N2-

23. Perform particle swipes on locations $1,2,3,4,5,6,7,8,15$ and 16 .

24. Stand the frame up in the vertical position and perform two Zonyl/rinse cycles on the lower castings

25. Dry off with N2-

26. Perform particle swipes on locations $9,10,11,12,13$ and 14 .

27. Contact Program Manager when complete. 
Old Process

\begin{tabular}{c|c|c|c|c|c|c|c|c|c|c|c|c|c|c|c|c|c|c} 
Frame & Process & $\mathbf{1}$ & $\mathbf{2}$ & $\mathbf{3}$ & $\mathbf{4}$ & $\mathbf{5}$ & $\mathbf{6}$ & $\mathbf{7}$ & $\mathbf{8}$ & $\mathbf{9}$ & $\mathbf{1 0}$ & $\mathbf{1 1}$ & $\mathbf{1 2}$ & $\mathbf{1 3}$ & $\mathbf{1 4}$ & $\mathbf{1 5}$ & $\mathbf{1 6}$ & Ave. \\
\hline 7585 & Pre-clean(1X), 2 Zonyl/2 Rinse (3X) & 190 & 184 & 96 & 119 & 76 & 92 & 65 & 55 & 70 & 110 & 105 & 88 & 99 & 98 & 105 & 117 & 104 \\
\hline 7491 & Pre-clean(1X), 1 Zonyl/1 Rinse (3X) & 134 & 123 & 76 & 84 & 83 & 128 & 72 & 79 & 91 & 73 & 97 & 96 & 89 & 87 & 83 & 103 & 94 \\
\hline 7577 & Pre-clean(1X), 1 Zony//1 Rinse (3X) & 162 & 119 & 86 & 85 & 76 & 96 & 87 & 86 & 76 & 94 & 106 & 110 & 105 & 102 & 91 & 98 & 99 \\
\hline 7147 & Pre-clean(1X), 1 Zonyl/1 Rinse (3X) & 181 & 139 & 111 & 107 & 82 & 67 & 92 & 65 & 79 & 102 & 80 & 72 & 83 & 68 & 92 & 98 & 95 \\
\hline & & 167 & 141 & $\mathbf{9 2}$ & 99 & 79 & 96 & $\mathbf{7 9}$ & $\mathbf{7 1}$ & $\mathbf{7 9}$ & $\mathbf{9 5}$ & $\mathbf{9 7}$ & $\mathbf{9 2}$ & $\mathbf{9 4}$ & 89 & 93 & 104 &
\end{tabular}

Revision D Process

\begin{tabular}{l|c|c|c|c|c|c|c|c|c|c|c|c|c|c|c|c|c|c}
7585 & Wipe (1X), 2 Zonyl/2 Rinse (1X) & 94 & 87 & 76 & 84 & 84 & 88 & 77 & 75 & 74 & 97 & 79 & 75 & & 81 & 61 & 93 & $\mathbf{8 2}$ \\
\hline 7585 & Additlonal 2 Brulin/2 Rinse (1X) & 100 & 99 & 76 & 89 & 84 & 70 & 75 & 53 & 62 & 82 & 68 & 79 & 78 & 63 & 69 & 78 & $\mathbf{7 7}$ \\
\hline 7492 & Wipe (3X), 2 Zonyl/2 Rinse (1X) & 94 & 97 & 71 & 62 & 54 & 67 & 58 & 63 & 69 & 79 & 87 & 78 & 74 & 60 & 68 & 63 & $\mathbf{7 2}$ \\
\hline 8647 & Wlpe (2X), 2 Zonyl/2 Rinse (2X) & 74 & 85 & 78 & 92 & 86 & 87 & 66 & 74 & 89 & 106 & 77 & 86 & 88 & 73 & 93 & 91 & $\mathbf{8 4}$ \\
\hline 8647 & Additlonal 2 Zonyl/2 Rinse (1X) & 92 & 81 & 97 & 102 & 83 & 98 & 63 & 74 & 77 & 70 & 69 & 68 & 81 & 91 & 84 & 83 & $\mathbf{8 2}$ \\
\hline & & 91 & 90 & $\mathbf{8 0}$ & 86 & $\mathbf{7 8}$ & $\mathbf{8 2}$ & $\mathbf{6 8}$ & $\mathbf{6 8}$ & $\mathbf{7 4}$ & $\mathbf{8 7}$ & $\mathbf{7 6}$ & $\mathbf{7 7}$ & $\mathbf{8 0}$ & $\mathbf{7 4}$ & $\mathbf{7 5}$ & $\mathbf{8 2}$ &
\end{tabular}

\section{Swipe Reading of Old vs. Revision D Procedure}

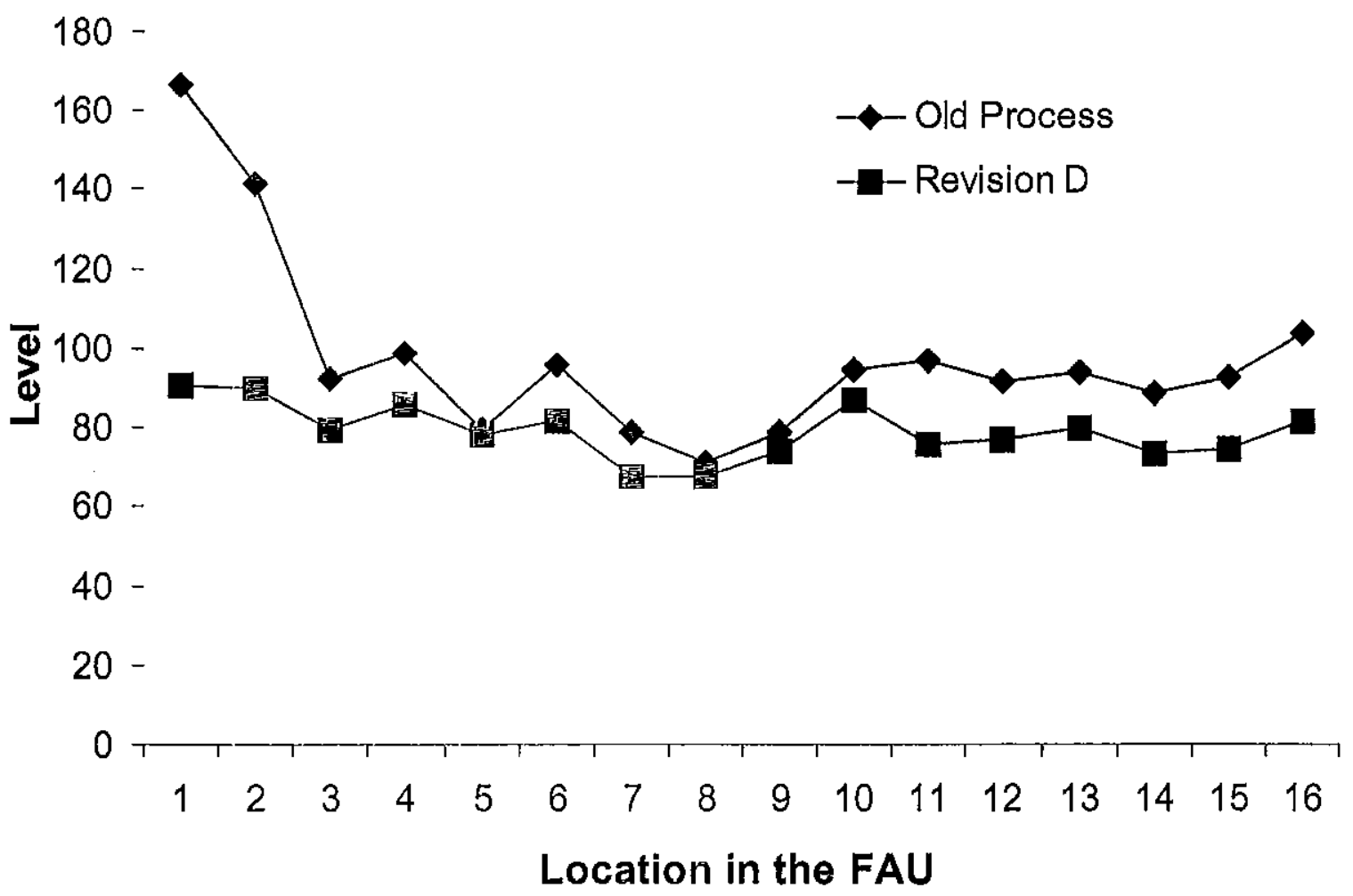

